\title{
AN EXPERIMENTAL INVESTIGATION ON RADIANT FLOOR HEATING SYSTEMS AT VARIOUS OPERATING CONDITIONS
}

\author{
Yakup Karakoyunn ${ }^{1, *}$, Özgen Açıkgöz ${ }^{2}$, Ahmet Selim Dalkılıç², Zehra Yumurtacı ${ }^{3}$
}

\begin{abstract}
In this study, heat transfer characteristics pertaining to a heated radiant floor are investigated experimentally. In order to achieve this aim, experiments have been conducted within extended supply water temperature ranging from $30^{\circ} \mathrm{C}$ to $55^{\circ} \mathrm{C}$, and mass flow rate ranging from $0.056 \mathrm{~kg} / \mathrm{s}$ to $0.125 \mathrm{~kg} / \mathrm{s}$ according to experimental condition ranges in the relevant literature. Correlation comparison has been accomplished using a large number of experimental data including pioneer studies and international standards regarding with the determination of heat flux and heat transfer coefficients. Moreover, novel correlations providing convective, radiative and total heat fluxes have been derived, and it has been observed that most of the outcomes of correlations remain within deviation bands of $\pm 15 \%, \pm 5 \%$ and $\pm 20 \%$, respectively. Apart from the literature, heat flux correlations corresponding to each heat transfer mechanisms are given and evaluated separately. Throughout experimental studies, the proportion of the radiative heat transfer to total one is found $60 \%$ approximately. Measured experimental data are given in the paper for other researchers validation problems on their theoretical and numerical works.
\end{abstract}

\section{Keywords: Natural Convection, Enclosure, Radiant Heating, Floor Heating, Energy Saving}

\section{INTRODUCTION}

Low temperature heating applications such as hydronic radiant heating systems are nowadays being prevalently utilized particularly in association with renewable energy sources due to high energy saving potential along with thermal comfort advantage. Using wide surfaces as heat sources results in surface temperature of living environments to increase, and improves indoor thermal conditions. Furthermore, by causing lower amounts of exergy destruction due to lower supply temperatures, these systems bring about remarkable gains with regard to energy efficiency.

Radiant heating and cooling systems are the frequently preferred air conditioning systems due to their advantages such as high thermal comfort and energy efficiency. Besides, these benefits of radiant heating/cooling systems also provide a homogeneous heat distribution, cooperation with supplementary systems including solar systems and heat pumps, and no extra need for mechanical equipment in the conditioned area, etc. Therefore, determining the heat transfer characteristics of a radiant heating/cooling system is the most important step in designing, dimensioning and defining thermal capacity, while the characteristics comprise radiative, convective, and total heat fluxes, as well as, radiative, convective, and total heat transfer coefficients. In the literature, it has been observed that various experimental and numerical studies have been conducted on radiant heating and cooling systems and their short summaries were given in the paragraphs below.

In a numerical study, Awbi [1] calculated the convective heat transfer coefficient of room surfaces under natural convection using two different turbulence models and compared their findings with experimental measurements. The two turbulence models are: a standard k- $\varepsilon$ model using "wall functions" and a low Reynolds number k- $\varepsilon$ model. It is observed that the low Reynolds number $k-\varepsilon$ model predicts the heat transfer coefficient more accurately compared to k- $\varepsilon$ model using wall functions. In the study of Hasan et al. [2], low temperature water heating systems are simulated with radiators in the rooms and floor heating in the bathroom. The requirement for the bathroom surface temperature is $27^{\circ} \mathrm{C}$, thus the $33-43 \%$ of the heating energy is used for that purpose. It is observed that the temperature fluctuations in the rooms are in limits of ASHRAE Standards 55-2004, four heating systems studied in this study fulfill the thermal comfort criteria. In a series of study Myhren and Holmberg

\footnotetext{
This paper was recommended for publication in revised form by Editor Tolga TANER

1,* Energy Division, Department of Mechanical Engineering, Hakkari University, Hakkari, Turkey

${ }^{2}$ Heat and Thermodynamics Division, Department of Mechanical Engineering, Yildiz Technical University, Istanbul, Turkey

${ }^{3}$ Energy Division, Department of Mechanical Engineering, Yildiz Technical University, Istanbul, Turkey

*E-mail address: yakupkarakoyun@hakkari.edu.tr

Orcid id: 0000-0003-1868-452X, 0000-0002-0095-829X, 0000-0002-5743-3937

Manuscript Received 29 January 2020, Accepted 20 April 2020
} 
[3,4]investigated numerically the flow patterns of thermal comfort in a room with panel, floor and wall heating and design considerations with ventilation radiators. It is observed that the low temperature systems improve indoor climate with better comfort conditions however the location of the heat emission and the design ventilation system is important to maintain the desired level of heating. The numerical results showed that the ventilation radiators create more comfortable thermal conditions than the traditional radiators ventilations systems. The same thermal conditions are achieved with ventilation radiators with lower heat capacity which indicates energy and environmental savings. Li et al. [5] conducted a simplified analysis to estimate the floor temperature distribution for radiant floor cooling system where the key parameter is preventing the condensation in floor surface based on consideration of the dew point in indoor environment. The surface temperature difference between the simplified analysis and the experimental observation is $0.4^{\circ} \mathrm{C}$. In the numerical study of Tye-Gingas and Gosselin [6], a semianalytical model is used to investigate the heat transfer characteristic for radiant panels with serpentine layout. The 2-D finite volume model is used as a verification tool and the large range of assumptions yielded negligible errors with proposed semi-analytical model. A comparative numerical study is carried out to investigate the heat transfer characteristic of floor heating and wall heating system by Karabay et al. [7]. It is concluded that the wall heating system shows better thermal performance and thermal comfort compared to floor heating. The environmental considerations are also reduced in wall heating systems.

In the study of Causone et al. [8], the limitations of floor heating and cooling with displacement ventilation is investigated experimentally. The effects of different environmental conditions are studied to obtain the temperature, air velocity profiles, surface temperatures and ventilation effectiveness. The measurements showed that the displacement ventilation guarantee high level indoor air quality and the use of floor cooling does not increase the draught risk at ankle level. In the experimental study Koca et al. [9] a climatic test chamber is constructed to characterize the heating capacity and heat transfer coefficient of a heated radiant wall system. It is observed that the radiant heat transfer dominated the convective heat transfer. The different configurations of the wall system is considered and did not effected radiation significantly (around $10 \%$ ) however the convective heat transfer is affected significantly (around 25\%). Bojic et al. [10] studied different energy sources and compared the energy efficiency combined with the environmental effects. Four different heating systems analyzed: floor radiant panels, wall radiant panels, ceiling radiant panels and new floor-ceiling radiant panels, and three different heating sources compared in terms of cost and $\mathrm{CO}_{2}$ emission: natural gas boiler, ground source heat pump (GSHP) and photovoltaic(PV) combined with GSHP. The best heating characteristic is evaluated for the new floor-ceiling radiant panels and GSHP lower the energy consumption compared to a system powered with natural gas. Seyam et al. [11] investigated experimentally and numerically the thermal comfort of a scale room model using electric heaters where the heating panels are installed on walls, floor and ceiling. The turbulent RNG k- $\varepsilon$ numerical method is used and good agreement with experimental observations is obtained. For the same heater surface temperature, heat flux reduced for increased heater size and the corresponding heat transfer coefficient decreased. The floor heating is most cost efficient. In an experimental study Rahimi and Sabernaeemi [12] investigated the radiation and free convection in an enclosure with radiant heating ceilings. It is observed that $90 \%$ of heat transferred by radiation and the radiation is enhanced with increased ceiling temperature.

In an experimental study Andres-Chicote et al. [13] studied the cooling capacity of a radiant cooled ceiling system. It is desired to relate the thermal comfort levels to operation conditions for cooling radiant ceiling system. It is concluded that the radiant and convective phenomena should be considered separately to obtain more realistic situations. Cholewa et al. [14] conducted an experimental study on heated cooled radiant floor to obtain a reference temperature for the calculation of heat transfer coefficient and heating cooling capacity of radiant floor systems. For the proposed system the values of radiant convective and heat transfer coefficients are developed by the use of proper reference temperature. Causone at al. [15] evaluated the heat transfer coefficient between radiant ceiling and the room in an experimental study using surface temperature distributions, internal gains and air movements. The heating and cooling enhancement is possible with higher convective heat transfer because the radiant heat transfer is constant. The proposed solution to improve the convection is to couple radiant system to ventilation system. Tian et al. [16] conducted an experimental study using an actual office environment to evaluate the cooling performance of ceiling radiant cooling panels (CRCP). The characteristic temperature difference of $8^{\circ} \mathrm{C}$ enhanced the cooling capacity of panes by $17.1 \%$ and the correction coefficient for the air velocity is between 1.02 and 1.26 under different conditions. In an experimental study Zhang et al. [17] investigated the heating and cooling performance of a suspended metal ceiling radiant panel (CRP) with inclined fins. It is observed that the cooling capacity of CRP with inclined fins enhanced with $19 \%$ compared to the suspended panel. In an experimental study 
of Li et al. [18], a radiant heating cooling ceiling panel system is investigated to clarify the system performance and tabulate reference data. The system performance is evaluated using its heating/cooling capacity and thermal comfort. The upward heat flux is found as $30-40 \%$ of the water heating/cooling capacity and several design proposals for reduction of upward heat flux are discussed. Fontana [19] investigated the effect of presence of furniture in the environment for lots of conditions with respect to the system performance of a radiant floor heating system experimentally. According to the study a radiant floor heating system cannot be designed without consideration of presence of furniture. While Açıkgöz et al. [20,21] studied the thermal behavior of the floor heating and cooling systems, Xia and Zhang [22] used the phase change materials as a new approach.

Açıkgöz and Kıncay [23] studied the heat transfer coefficients of a real sized room which cooled from wall, and the study consists of two parts as experimental and numerical. Another work done numerically and theoretically by Açıkgöz [24], considered the effect of emissivity of surfaces on the heat transfer coefficient in a radiant system. Based on his study it is revealed that for a room, the radiative heat transfer coefficient varies in a range of 5.4-5.5 W/m $\mathrm{m}^{2} \mathrm{~K}$. Açıkgöz and Kıncay [25] investigated the effect of the wall temperature on the heat transfer coefficients based on 2-D and 3-D numerical simulation of a real sized room. In order to predict the heat transfer coefficients Açıkgöz et al. [26] proposed an ANN model and validated it with experimental results. Authors showed the possibility of doing numerical analysis on this subject in order to at values in their works and substantive with some additional physics.

A study conducted by Hu and Niu [27] indicates that there have still been problems related to estimation of heating/cooling capacity of such systems that result in the higher energy consumption and thermal discomfort. One of the most important reasons of this improper load estimation is associated with wide range of errors that arise from when assigning the heat transfer coefficients which identify the thermal behavior of radiant heating and cooling systems. As it is stated in the work of Shinoda et al. [28] that a comprehensive review based on the heat transfer coefficients over radiant surfaces, while the radiant heat transfer coefficients have compatible values with literature and standards, the convective and total heat transfer coefficients give different results in a wide range, even for the same conditions. Cholewa et al. [14] concluded that the heat transfer coefficients available in the literature are overestimated even in the range of 10-30\%. According to study related to convective heat transfer characteristics in radiant systems performed by Peeters et al. [29], it is revealed that while radiation and conduction heat transfer can be defined easily using numerical and analytical models, the convective heat transfer is a more complicated phenomenon.

According to the literature survey, many experimental and numerical studies have been conducted on determination of the radiative, convective, and total heat transfer coefficients of radiant heating/cooling systems. However, experimental studies in the relevant literature have been performed within narrow supply water temperature and flow rate ranges. Therefor, operating condition range has been widened, and the experiments have been conducted within extended supply water temperature and flow rate ranges of from $30{ }^{\circ} \mathrm{C}$ to $55^{\circ} \mathrm{C}$ and from $0.056 \mathrm{~kg} / \mathrm{s}$ to $0.125 \mathrm{~kg} / \mathrm{s}$, respectively. From this point of view, the present paper defines the proper heat transfer coefficients (radiative, convective, and total) experimentally for the investigated radiant floor heating system in a real size enclosure.

In addition, unlike most of other studies having only a combined total heat flux correlation involving both convection and radiation in a single form, this study has derived empirical correlations for convective, radiative, and total heat fluxes from a radiant heated floor separately.

\section{EXPERIMENTAL SETUP}

Accurate results can only be obtained via test rooms designed to work under steady state conditions. For this purpose, a reliable test room is established in a laboratory, shown in Figure 1, for studying characteristics pertaining to an underfloor heating system. The square floor has a length of $1.8 \mathrm{~m}$, and the height of the room is $2.85 \mathrm{~m}$. The test room is insulated to reach and maintain the steady state conditions at an acceptable duration. Therefore, obtained results can be considered as accurate and tolerable. Schematic representation and formation process of the test room is shown in Figure 1 (a-e). A photo of experimental setup including its main components, primary and secondary supply water lines is given in Figure 2 (a) and 2 (b), respectively. 


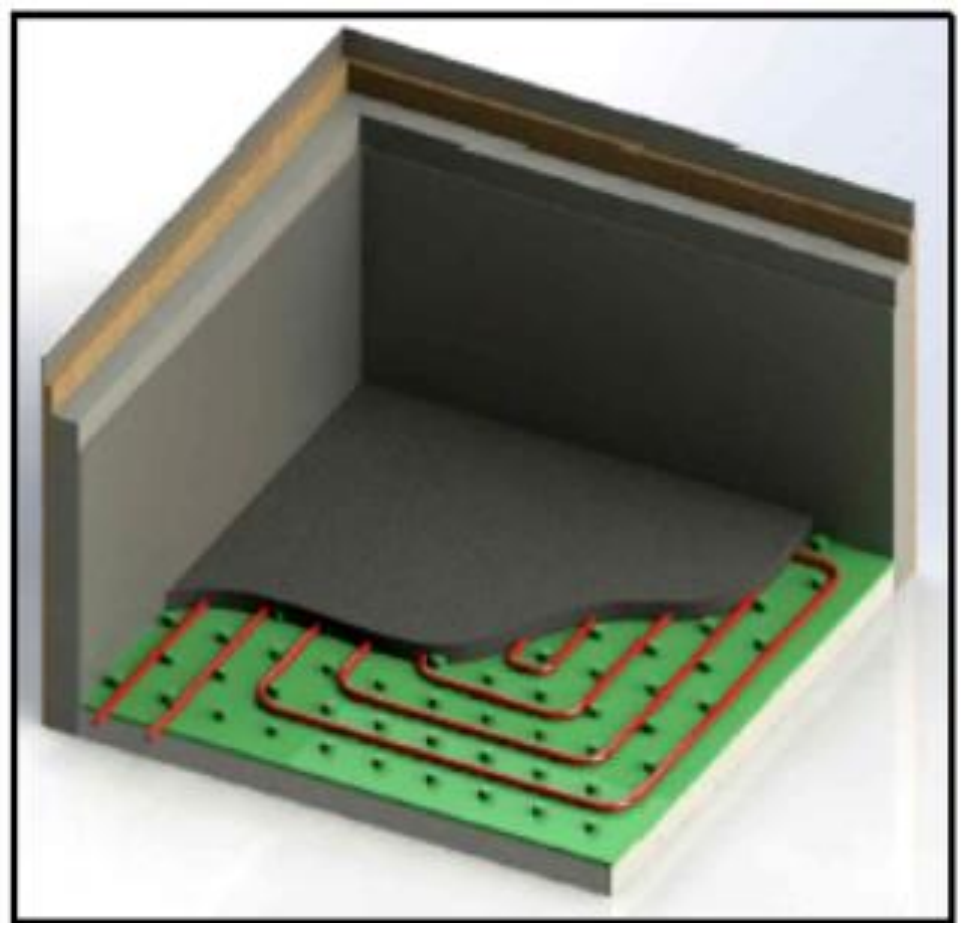

(a)

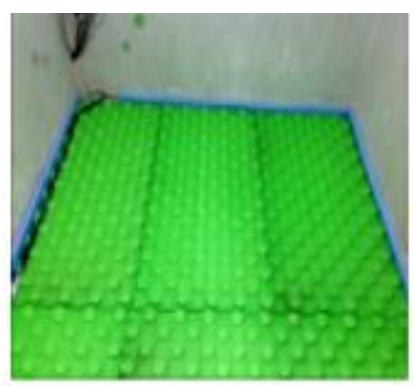

(b)

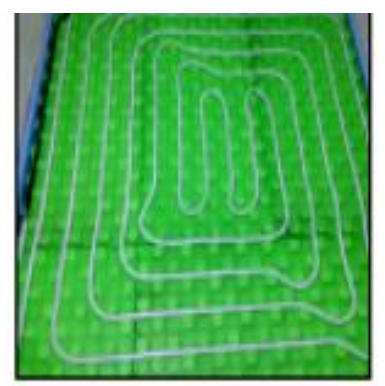

(c)

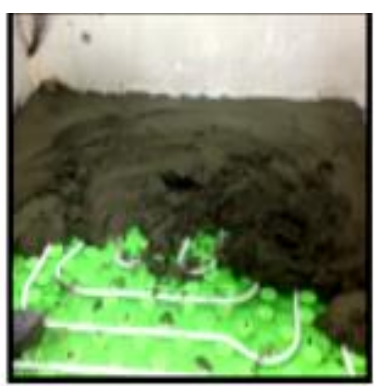

(d)

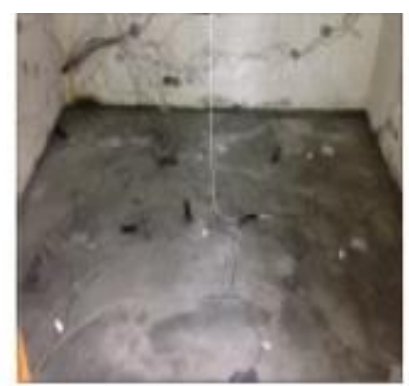

(e)

Figure 1. Schematic build up representation (a) and photographic illustration (b-e) of the test room

The distance between the buried pipes into the floor of test room is $12 \mathrm{~cm}$. The pattern of the pipe arrangement is as shown in Figure 3 (a). The temperature values of the test room surfaces are measured with thirtyfour $\mathrm{T}$ type thermocouples that has been calibrated with a $0.4 \%$ precision. Five thermocouples are placed on each side walls and ceiling surfaces, and nine on the radiant floor of the test room. The configuration of thermocouples is shown in Figure 3 (b). The temperature measurements using the proposed thermocouple configuration demonstrate homogeneous temperature distribution. The constant and homogeneous temperature distribution enables the accurate radiant heat transfer calculations. The air temperature measurements are carried out using two thermocouples located at two different heights, $110 \mathrm{~cm}$ and $140 \mathrm{~cm}$. The emissivity of the test room surfaces is evaluated using thermocouples and infrared thermal camera.

Two calibrated PT100 type sensors are used to measure the supply water inlet and outlet temperatures. The experimental setup consists of two different heating circuits. The primary circuit is comprised of a heating tank, pump and a heat exchanger where the water circulates between the heating tank and the heat exchanger. The secondary circuit is in charge of heating the water that heats the test room. The flow rate of the water is measured using the flowmeter with $0.1 \%$ precision, and the desired amount of water is delivered to the chamber through the heat exchanger. The inlet and outlet supply water temperatures to the heating circuit are measured just before and after the water enters and leaves the circuit, respectively. Thus, the rate of transferred heat to the test chamber is obtained. 


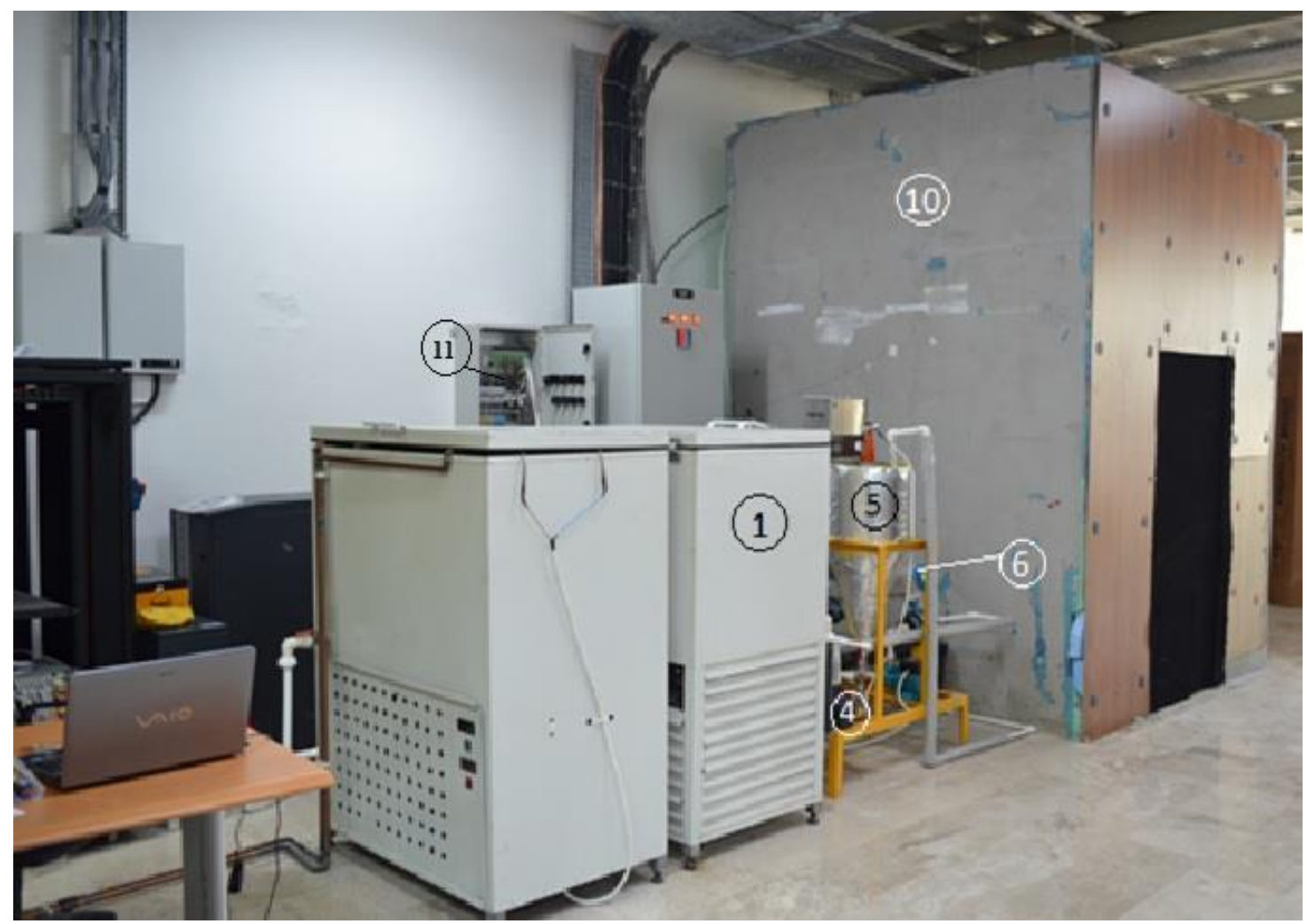

(a)

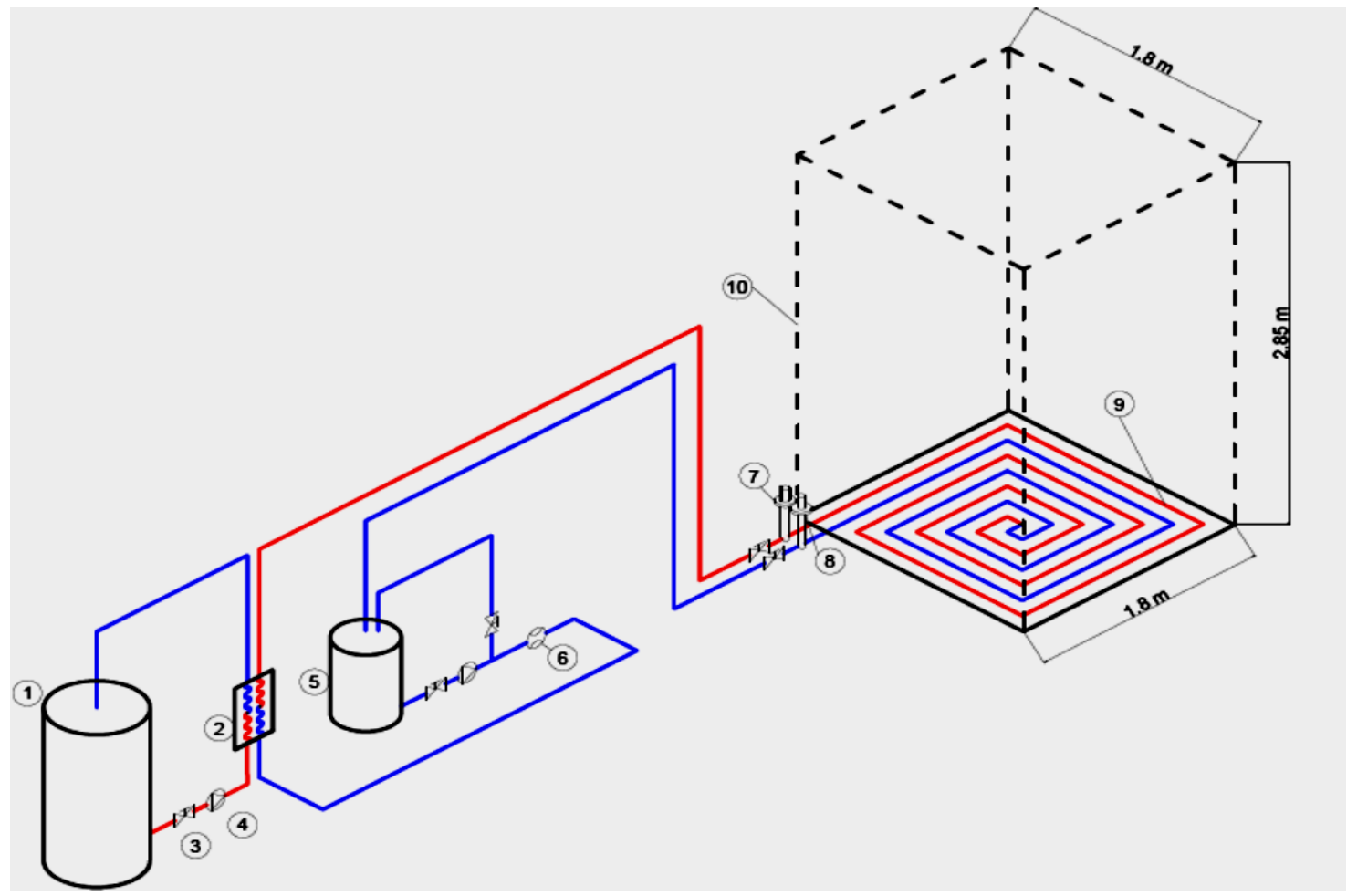

(b)

Figure 2. Settlement of the setup in the laboratory (a) and sketch of the test chamber alongside hot water preparation equipment (b)

1. Heat storage water tank 2. Heat exchanger 3. Valve 4. Pump 5. Water supplier 6. Flow meter 7. PT100-hot line 8. PT100cold line 9. Pipes 10. Test chamber 11. PLC 


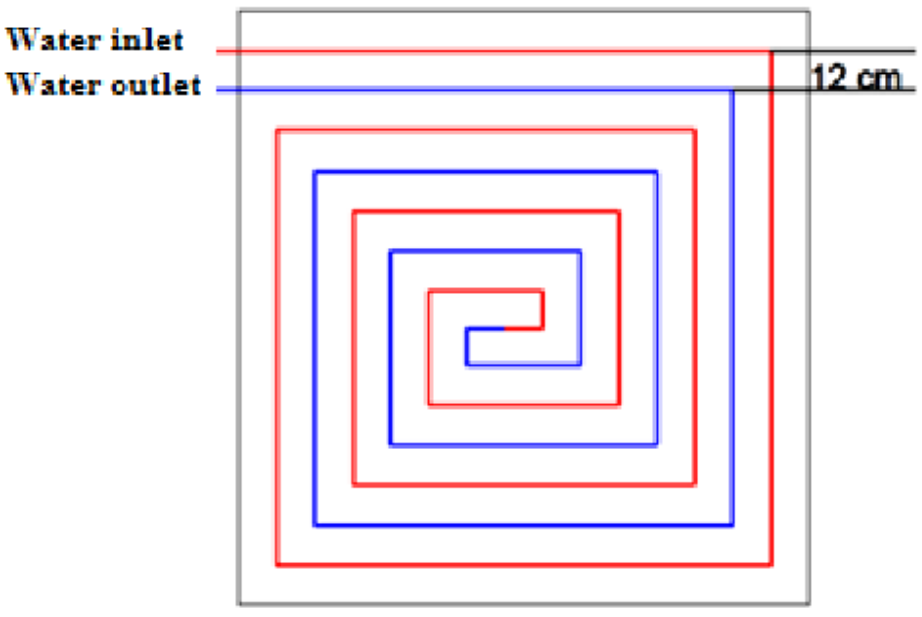

(a)

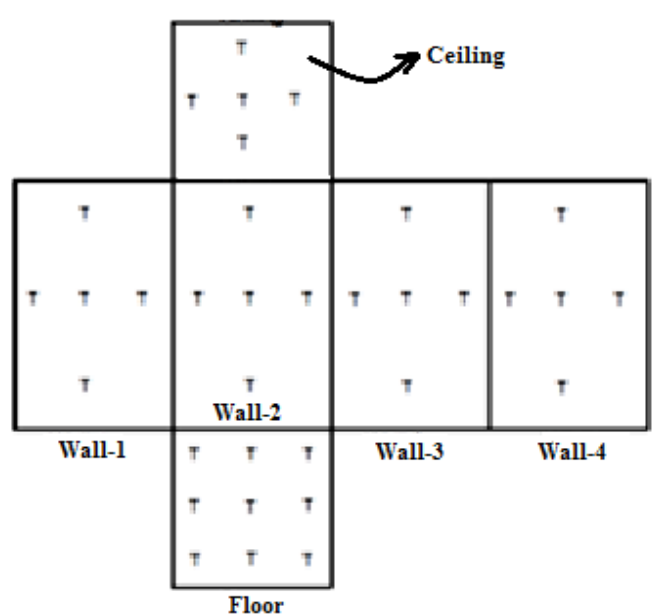

(b)

Figure 3. Pattern of the pipe arrangement in the test room (a), the thermocouple configurations along the side walls, ceiling and the floor (b)

The experiments are carried out at three different supply water mass flow rates of $0.056 \mathrm{~kg} / \mathrm{s}, 0.090 \mathrm{~kg} / \mathrm{s}$, and $0.125 \mathrm{~kg} / \mathrm{s}$ and six different supply water temperatures from $30{ }^{\circ} \mathrm{C}$ to $55^{\circ} \mathrm{C}$, by $5{ }^{\circ} \mathrm{C}$ temperature intervals. Hence, the calculations are conducted under different heating loads. The measured data are recorded at every 5 minutes on PC using a PLC, and the ultimate measurements are acquired after the steady state is reached. It shoul be noted that throughout the experiments this has taken approximately $8-9$ hours.

\section{CALCULATION METHODOLOGY OF THE HEAT TRANSFER COEFFICIENTS}

In this section, the calculation procedure of heat transfer characteristics for the radiant floor heating system is given. The total heat transferred from supply water to the test chamber is calculated according to Eq. (1) in steady state condition. The temperature difference is determined by measuring the difference between the supply water inlet and outlet temperature to the circuit.

$$
\dot{Q}_{s}=\dot{m}_{w} C_{p}\left(T_{s}-T_{r}\right)
$$

The total heat transferred to the room can be considered as the summation of the heat transferred via radiation and convection as seen in Eq. (2).

$$
\dot{Q}_{t}=\dot{Q}_{r}+\dot{Q}_{c}
$$

The total heat transfer coefficient between the radiant floor surface and test chamber can be obtained using Eq. (3).

$$
h_{t}=\frac{\dot{Q}_{t}}{A\left(T_{f}-T_{o p}\right)}
$$

The calculation of radiant heat transfer characteristics is based on the determination of reference temperature named average unheated surface temperature (AUST) and it is given in Eq. (4). It has been commonly used by the researchers $[9,14,15]$ in the literature.

$$
A U S T=\sqrt[4]{\sum_{j=1}^{n}\left(F_{s-j} T_{j}^{4}\right)}
$$


To obtain the radiation interchange factor and afterward to calculate radiant heat flux, Eq.(5) ang Eq.(6) are employed, respectively, and this calculation procedure along with its details exists in relavant publications $[9,14,15]$.

$$
\begin{gathered}
F \varepsilon_{s-j}=\frac{1}{\left(\frac{1-\varepsilon_{s}}{\varepsilon_{s}}\right)+\left(\frac{1}{F_{s-j}}\right)+\left(\frac{A_{s}}{A_{j}}\right)\left(\frac{1-\varepsilon_{j}}{\varepsilon_{j}}\right)} \\
q_{r}=\sigma \sum_{j=1}^{n} F \varepsilon_{s-j}\left(T_{s}^{4}-T_{j}^{4}\right)
\end{gathered}
$$

3-D Matlab code is utilized to find out the radiative heat transfer rate between the radiant floor and other surfaces. Whilst the program is being operated of which interface is illustrated in Figure 4, all surface temperatures, surface dimensions, and surface emissivity values $(\mathcal{E})$ are input to the program. The value of emissivities considered in the analyses is 0.9 . It should also be noted that data conveyed to the program is recurred for each experimental case study.

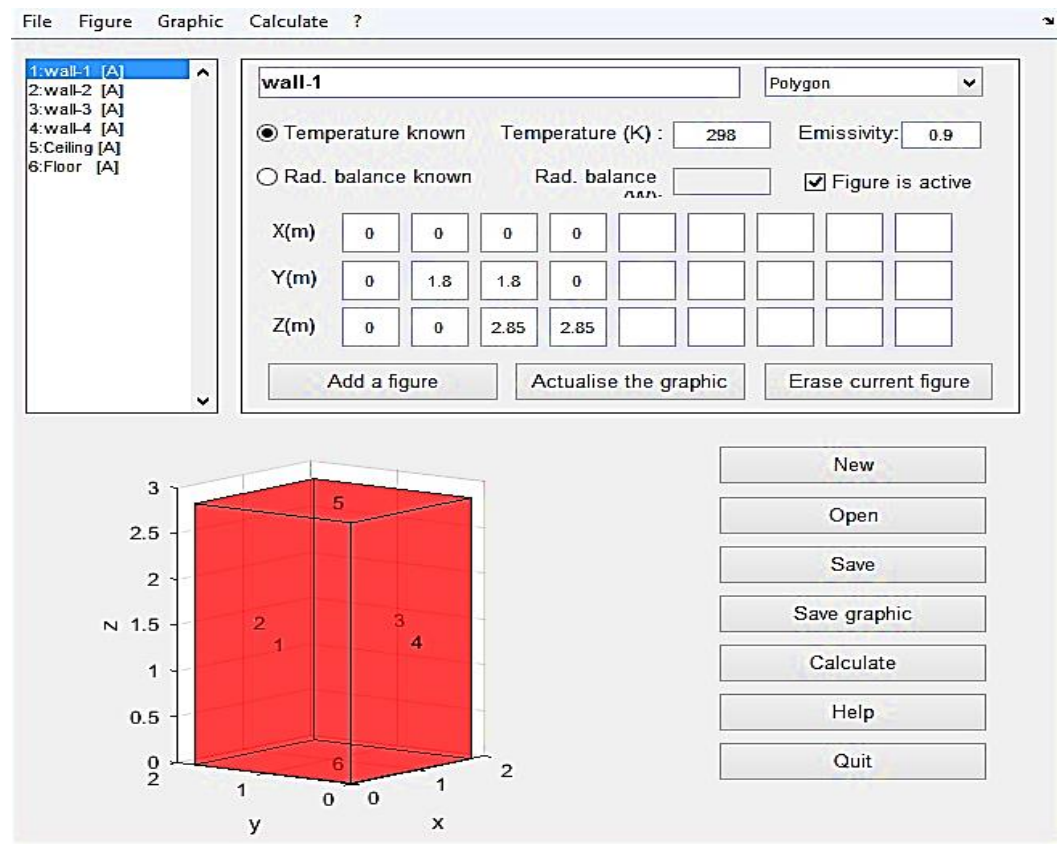

Figure 4. Investigated model in radiation heat transfer software Eq. (7).

The radiant heat transfer coefficient $\left(h_{r}\right)$ between heated floor and its surroundings is determined using

$$
h_{r}=\frac{\sigma \sum_{j=1}^{n} F \varepsilon_{s-j}\left(T_{s}^{4}-T_{j}^{4}\right)}{A U S T-T_{f}}
$$

The convective heat flux can be calculated via Eq. (8). According to equation, radiant heat flux is extracted from the total heat flux from the floor to find the convective heat flux.

$$
q_{c}=q_{t}+q_{r}
$$


With respect to all above mentioned equations, convective heat transfer coefficient between the radiant floor and air can be ascertained using Eq. (9). In this equation, as suggested by Cholewa et al. [14] and Causone et al. [15] for a standing person, air temperature at the height of $1.1 \mathrm{~m}$, from the floor is selected as reference temperature.

$$
h_{c}=\frac{q_{c}}{T_{f}-T_{a}}
$$

Rayleigh numbers are calculated by Eq. (10), where L represents the characteristic length, $\beta\left(\mathrm{K}^{-1}\right)$ is the thermal expansion coefficient and $v\left(\mathrm{~m}^{2} / \mathrm{s}\right)$ is the kinematic viscosity. In equation, $\mathrm{g}\left(\mathrm{m} / \mathrm{s}^{2}\right)$ presents the gravitational constant and $\mathrm{Pr}$ is the Prandtl number. It should be noted that throughout the evaluations, the range of Rayleigh numbers have varied within the range of $2.4 \times 10^{7}$ to $8.3 \times 10^{7}$.

$$
R a=\left[g \beta\left(T_{f}-T_{a}\right) \frac{L^{3}}{v^{2}}\right] \operatorname{Pr}
$$

\section{Uncertainty analysis}

While analyzing the experimental results, knowing the range of errors that affects the precision of outputs is necessary. In experimental works, errors may arise from two main sources as errors caused by component of experimental setup and measurement tools, and human factors. In order to define the experimental uncertainties, a method proposed by Kline and McClintock [30] has implemented. In Eq. (11) U is the measured parameter and is a function of independent variables as $\mathrm{x}_{1}, \mathrm{x}_{2}, \mathrm{x}_{3}, \ldots . \mathrm{x}_{\mathrm{n}}$.

$$
U=U\left(x_{1}, x_{2}, x_{3}, \ldots, x_{n}\right)
$$

The uncertainties of each independent variables that affect the $\mathrm{U}$ parameter is given as $\mathrm{w}_{1}, \mathrm{w}_{2}, \mathrm{w}_{3}, \ldots, \mathrm{w}_{\mathrm{n}}$. Afterward, the uncertainties of experimental results can be calculated based on the following equation (Eq. 12).

$$
w_{U}= \pm\left[\left(\frac{\partial U}{\partial x_{1}} w_{1}\right)^{2}+\left(\frac{\partial U}{\partial x_{2}} w_{2}\right)^{2}+\left(\frac{\partial U}{\partial x_{3}} w_{3}\right)^{2}+\ldots+\left(\frac{\partial U}{\partial x_{n}} w_{n}\right)^{2}\right]^{1 / 2}
$$

The uncertainty values of examined parameters which are radiative, convective, and total heat fluxes, and radiation, convection, and total heat transfer coefficients are found and demonstrated in Table (1).

Table 1. Uncertainties of experimental results

\begin{tabular}{|l|l|}
\hline Parameters & Uncertainty \\
\hline $\mathbf{q}_{\text {total }}$ & $\pm \% 1.3$ \\
\hline $\mathbf{q r a d}_{\text {rad }}$ & $\pm \% 0.2$ \\
\hline $\mathbf{q}_{\text {con }}$ & $\pm \% 3.7$ \\
\hline $\mathbf{h}_{\text {total }}$ & $\pm \% 5.8$ \\
\hline $\mathbf{h}_{\text {rad }}$ & $\pm \% 4.1$ \\
\hline $\mathbf{h}_{\text {con }}$ & $\pm \% 11.5$ \\
\hline
\end{tabular}




\section{RESULTS AND DISCUSSION}

Radiant floor systems enable enhanced thermal comfort compared to tradiational HVAC systems due to advances in suitable surface temperature and air movement which allows to decrease draught discomfort and bring about better homogenous temperature distribution within the living environment. Contrary to radiant floor cooling systems, free convection over radiant heated floor plays an important role in heating applications for radiant floor.In these systems, it is presumable to have lower fluid temperatures under winter conditions in order to correspond thermal capacity. Thus, energy efficiency of the heat supplying devices and decrease in energy consumption are obtained finally.

In relation to the compatibility issue with pioneer studies in the literature, operative temperature for total heat transfer coefficient $\left(h_{t}\right)$ and air temperature for convective heat transfer coefficient $\left(h_{c}\right)$ values at the height of $1.1 \mathrm{~m}$ from the floor (as suggested by Causone et al. [15] for a standing person) are selected. To use as a source of comparison regarding the relevant literature, for convective heat transfer coefficient $\left(h_{c}\right)$, as used by Awbi and Hatton [31], air temperature at $1.4 \mathrm{~m}$ from the floor is also considered in this work. Additionally, in radiative heat transfer calculations, average unheated surface temperature (AUST) has been employed [32]. These information is summed up in Table 2. According to Chicote et al. [13],evaluating the total heat transfer mechanisms, the operative temperature cannot be selected as only reference, and the paper proposes radiant and convective terms to be separately assesessed. From this point of view, novel equations corresponding to each phenomenon have been derived.

Table 2. Reference temperatures [15]

\begin{tabular}{|c|c|c|}
\hline $\begin{array}{c}\text { Heat transfer } \\
\text { coefficient }\end{array}$ & $\begin{array}{c}\text { Reference temperature } \\
\left(\mathbf{T}_{\text {ref }}\right)\end{array}$ & $\begin{array}{c}\text { Temperature } \\
\text { difference }\end{array}$ \\
\hline $\mathbf{h}_{\mathbf{c}}$ & $\mathrm{T}_{\mathrm{a} 1.1}, \mathrm{~T}_{\mathrm{a} 1.4}$ & $\mathrm{~T}_{\mathrm{ref}}-\mathrm{T}_{\mathrm{f}}$ \\
\hline $\mathbf{h}_{\mathbf{r}}$ & $\mathrm{AUST}$ & $\mathrm{T}_{\mathrm{ref}}-\mathrm{T}_{\mathrm{f}}$ \\
\hline $\mathbf{h}_{\mathbf{t}}$ & $\mathrm{T}_{\mathrm{op} 1.4}$ & $\mathrm{~T}_{\mathrm{ref}}-\mathrm{T}_{\mathrm{f}}$ \\
\hline
\end{tabular}

Results acquired via real-size experimental setups such as the experimental chamber, and its supply water preparation equipment in the present investigation, provide most dependable outcomes. From this point of view, different case studies pertaining to a radiant floor heating system were performed to estimate its heat transfer characteristics. Heat transfer characteristics involve radiative, convective, and total heat fluxes, as well as, radiative, convective, and total heat transfer coefficients arising through the heated radiant floor. Throughout the experiments, six different supply water temperatures spanning between $30^{\circ} \mathrm{C}$ and $55^{\circ} \mathrm{C}$, and three different supply water flow rates $(0.056,0.090$, and $0.125 \mathrm{~kg} / \mathrm{s})$ have been applied. It should also be noted that the whole measurements were ended, when all the measurements reached steady state conditions, and these ultimate values were taken into account in calculations related to heat transfer characteristics.

Details of total 18 set of measurements, along with calculations pertaining each of them are observed in Table 3 (a-c), while each option belongs to a different water flow rate performed in the experiments. It can be noticed from the results that as the supply water temperature increases, heat outputs also increase with regard to radiative, convective, and total outputs. Figures 6 (a-c) illustrate the change of all heat outputs with corresponding temperature difference values. As expected, it is clear that with increasing temperature differences, thermal outputs result also in a raise. However, since radiation and convection have completely diverse phenomena, they both follow a different trend line. Additionally, it can be noticed that radiative heat outputs points follow a more steady distribution, whereas, convective output points follow a slightly more scattered distribution. This arises from the fact that radiative heat transfer calculations are conducted via theoretical calculations based on the net - radiosity method, and thus unavoidable experimental errors are involved in convective, and total heat transfer calculations.

To validate the heat output results of the present work, the total output correlation presented in EN 12642 [33], and the study of Cholewa et al. [14] which contains outcomes pertaining to a radiant floor heating, were chosen as benchmarks. Figures 7 (a-c) indicate the comparison of the radiative, convective, and total heat output results of the present investigation with that of mentioned in the previous sentence. It is evident from Figure 7a that the radiative heat output data of referenced study is almost follow the same trend line with that of this study 
and thus it can be noted that two investigations are consistent with each other, in terms of radiative heat transfer. Figure 7 (b) reveals the comparison of the convective results of the current study with relevant literature. As stated in the previous paragraph regarding reason for the slightly more scattered dispersion of convective data, the same behavior of this phenomenon can also be met in this figure. As it is indicated before, determination of convective heat transfer is generally difficult among all other heat transfer mechanisms while radiative and convective heat transfers can be determined via numerical and analytical methods. The reason of this behavior has been justified in the previous paragraph. Figure 7 (c) gives the comparison among three different studies in terms of total heat outputs, including the present investigation. It can be seen through the figure that three investigations keep track of each other, while the results of EN 1264-2 [33] are slightly higher than the the results of current investigation which means higher energy consumption. It is also noticed that the less scattered dispersion of radiative data, which composes outweighing portion of overall heat transfer through the heated floor and also presented in Figure 7 (a), turns total heat output data in Figure 7 (c) into a more straight dispersion.

Furthermore, through the data acquired via this investigation, new correlations regarding radiative, convective, and total heat flux density from a radiant heated floor have been derived and are presented by Eqs. $(13,14$, and 15), respectively. Figures 8 (a-c) illustrate the deviation of gained experimental data from those of obtained through correlations.

$$
\begin{gathered}
q_{r}=5.26\left(T_{f}-A U S T\right)^{1.04} \\
q_{c}=3.3\left(T_{f}-T_{a}\right)^{1.02} \\
q_{t}=9.55\left(T_{f}-T_{o p}\right)^{1.03}
\end{gathered}
$$

It is seen that when the experimental findings are compared with those obtained via derived radiative, convective, and total heat flux correlations, the $\mathrm{R}^{2}$ values of $0.99,0.88$, and 0.97 are attained, respectively. Thus it is deduced that the experiments have been performed within an acceptable accuracy. As it can be seen from Figure 8 (b) some of the data fall out of the deviation band due to uncertainty issue because it is hard to measure very small differences between inlet and outlet supply water temperatures. Beside this, all of the measured data are within the deviation band of $\pm 20 \%$ at high temperature differences, as shown in Figure 8 (b).

Heat transfer coefficients are key parameters in the designing, dimensioning, and thermal capacity determination of radiant heating and cooling systems. In case the relevant literature is rigorously reviewed, one can observe that rather than the radiative heat transfer coefficient which corresponds to radiation phenomenon, and is calculated by means of a theoretical method expressed in the previous paragraphs, the determinant parameter which also influence total heat transfer coefficient and thus total heat output is the convective heat transfer coefficient. Figures 9 (a-c) show the change of convective heat transfer coefficients attained via this study and comparison with works through which correlations have been derived. It can clearly be understood from the figures that the correlations found by Awbi and Hatton [31], and Min et al. [32] slightly overestimate convective heat transfer coefficients with the average proportional distances of $15 \%$, and $26 \%$ to the present investigation. Along with the unavoidable experimental measurement errors which may explain the deviations between the studies mentioned, differences in heated surface temperature range, whether any other heated or cooled surface within the chamber exist or not, conductive heat losses and gains considered or not, may account for the differences in Figures 9 (a-c). Furthermore, compared to the results pertaining to referenced studies seen in these figures that seem to have a steady dispersion, the points relating to the present investigation appear to draw a relatively more scattered dispersion. This is due to the fact that rather than the radiative heat transfer characteristic determined via theoretical methods, experimental errors are included in convective heat transfer calculations. 
Journal of Thermal Engineering, Research Article, Vol. 6, No. 5, pp. 751-771, October, 2020

Table 3. Measured values and calculated heat transfer characteristics in case the mass

\begin{tabular}{|c|c|c|c|c|c|c|c|c|c|c|c|c|c|}
\hline \multicolumn{14}{|c|}{$\dot{m}=0.056 \mathrm{~kg} / \mathrm{s}$} \\
\hline & \multicolumn{6}{|c|}{ Measured values } & \multicolumn{7}{|c|}{ Calculated values } \\
\hline $\begin{array}{l}\text { Test } \\
\text { descriptor }\end{array}$ & $\begin{array}{c}\mathrm{T}_{\mathrm{s}} \\
\left({ }^{\circ} \mathrm{C}\right)\end{array}$ & $\mathrm{T}_{\mathrm{w}}$ & $\mathrm{T}_{\mathrm{c}}$ & $\mathrm{T}_{\mathrm{f}}$ & $\mathrm{T}_{\mathrm{a} 1.1}$ & $\mathrm{~T}_{\mathrm{a} 1.4}$ & AUST & $\mathrm{q}_{\mathrm{r}}$ & $\mathrm{q}_{\mathrm{c}}$ & $\mathrm{q}_{\mathrm{t}}$ & $\mathrm{h}_{\mathrm{c}}$ & $\mathrm{h}_{\mathrm{r}}$ & ht \\
\hline 1 & 30 & 24.1 & 24.7 & 27.4 & 24.7 & 24.7 & 24.2 & 20.1 & 11.9 & 32.0 & 4.4 & 6.3 & 11.9 \\
\hline 2 & 35 & 24.7 & 25.7 & 31.1 & 25.7 & 25.6 & 24.9 & 34.9 & 14.8 & 49.8 & 2.8 & 5.6 & 9.2 \\
\hline 3 & 40 & 24.9 & 26.4 & 34.2 & 26.4 & 26.4 & 25.2 & 50.2 & 26.0 & 76.2 & 3.4 & 5.6 & 9.8 \\
\hline 4 & 45 & 27.4 & 29.0 & 38.2 & 29.1 & 29.1 & 27.6 & 61.0 & 22.7 & 83.7 & 2.5 & 5.8 & 9.3 \\
\hline 5 & 50 & 27.4 & 29.7 & 40.9 & 29.6 & 29.5 & 27.9 & 76.6 & 37.1 & 113.7 & 3.3 & 5.9 & 10.0 \\
\hline 6 & 55 & 31.2 & 32.2 & 44.6 & 32.1 & 32.0 & 31.3 & 80.6 & 48.4 & 129.0 & 3.9 & 6.1 & 10.3 \\
\hline \multicolumn{14}{|c|}{$\dot{m}=0.125 \mathrm{~kg} / \mathrm{s}$} \\
\hline & \multicolumn{6}{|c|}{ Measured values } & \multicolumn{7}{|c|}{ Calculated values } \\
\hline $\begin{array}{l}\text { Test } \\
\text { descriptor }\end{array}$ & $\begin{array}{l}\mathrm{T}_{\mathrm{s}} \\
\left({ }^{\circ} \mathrm{C}\right)\end{array}$ & $\mathrm{T}_{\mathrm{w}}$ & $\mathrm{T}_{\mathrm{c}}$ & $\mathrm{T}_{\mathrm{f}}$ & $\mathrm{T}_{\mathrm{a} 1.1}$ & $\mathrm{~T}_{\mathrm{a} 1.4}$ & AUST & $\mathrm{q}_{\mathrm{r}}$ & $\mathrm{q}_{\mathrm{c}}$ & $\mathrm{q}_{\mathrm{t}}$ & $\mathrm{h}_{\mathrm{c}}$ & $\mathrm{h}_{\mathrm{r}}$ & ht \\
\hline 1 & 30 & 24.7 & 25.1 & 28.18 & 25.21 & 25.15 & 24.8 & 18.57 & 12.7 & 31.3 & 4.3 & 5.42 & $\overline{10.6}$ \\
\hline 2 & 35 & 26 & 26.7 & 31.69 & 26.75 & 26.7 & 26.1 & 31.18 & 15.8 & 46.99 & 3.2 & 5.54 & 9.51 \\
\hline 3 & 40 & 26 & 27.5 & 34.81 & 27.43 & 27.32 & 26.3 & 48.11 & 26.7 & 74.84 & 3.62 & 5.64 & 10.1 \\
\hline 4 & 45 & 27.7 & 29.5 & 38.4 & 29.41 & 29.31 & 28.1 & 59.68 & 35.4 & 95.1 & 3.94 & $\begin{array}{l}5.8 \\
\end{array}$ & 10.6 \\
\hline 5 & 50 & 28.4 & 30.6 & 41.51 & 30.5 & 30.34 & 28.8 & 74.68 & 43.8 & 118.5 & 3.98 & 5.89 & 10.8 \\
\hline 6 & 55 & 31 & 33.4 & 45.63 & 33.25 & 33.08 & 31.5 & 86.57 & 52 & 138.5 & 4.2 & 6.1 & 11.2 \\
\hline \multicolumn{14}{|c|}{$\dot{m}=0.090 \mathrm{~kg} / \mathrm{s}$} \\
\hline & \multicolumn{6}{|c|}{ Measured values } & \multicolumn{7}{|c|}{ Calculated values } \\
\hline $\begin{array}{l}\text { Test } \\
\text { descriptor }\end{array}$ & $\begin{array}{l}\mathrm{T}_{\mathrm{s}} \\
\left({ }^{\circ} \mathrm{C}\right)\end{array}$ & $\mathrm{T}_{\mathrm{w}}$ & $\mathrm{T}_{\mathrm{c}}$ & $\mathrm{T}_{\mathrm{f}}$ & $\mathrm{T}_{\mathrm{a} 1.1}$ & $\mathrm{~T}_{\mathrm{a} 1.4}$ & AUST & $\mathrm{q}_{\mathrm{r}}$ & $\mathrm{q}_{\mathrm{c}}$ & $\mathrm{q}_{\mathrm{t}}$ & $\mathrm{h}_{\mathrm{c}}$ & $\mathrm{h}_{\mathrm{r}}$ & ht \\
\hline 1 & 30 & 22.3 & 23.1 & 27.48 & 23.13 & 23.06 & 22.4 & 26.37 & 13.3 & 39.7 & 3.02 & 5.24 & 9.13 \\
\hline 2 & 35 & 24.1 & 25.2 & 31.15 & 25.25 & 25.19 & 24.4 & 36.85 & 13.8 & 50.64 & 2.31 & 5.42 & 8.57 \\
\hline 3 & 40 & 26.1 & 27.4 & 34.72 & 27.42 & 27.35 & 26.3 & 47.5 & 26.9 & 74.43 & 3.66 & 5.64 & 10.2 \\
\hline 4 & 45 & 27.6 & 29.3 & 38.27 & 29.26 & 29.22 & 27.9 & 59.91 & 35.6 & 95.47 & 3.93 & 5.79 & 10.6 \\
\hline 5 & 50 & 28.3 & 30.5 & 41.41 & 30.39 & 30.31 & 28.8 & 74.67 & 39.8 & 114.4 & 3.58 & 5.9 & 10.4 \\
\hline 6 & 55 & 29.7 & 32.2 & 44.77 & 32.09 & 32.02 & 30.3 & 87.64 & 49.9 & 137.5 & 3.91 & 6.05 & 10.8 \\
\hline
\end{tabular}


Journal of Thermal Engineering, Research Article, Vol. 6, No. 5, pp. 751-771, October, 2020

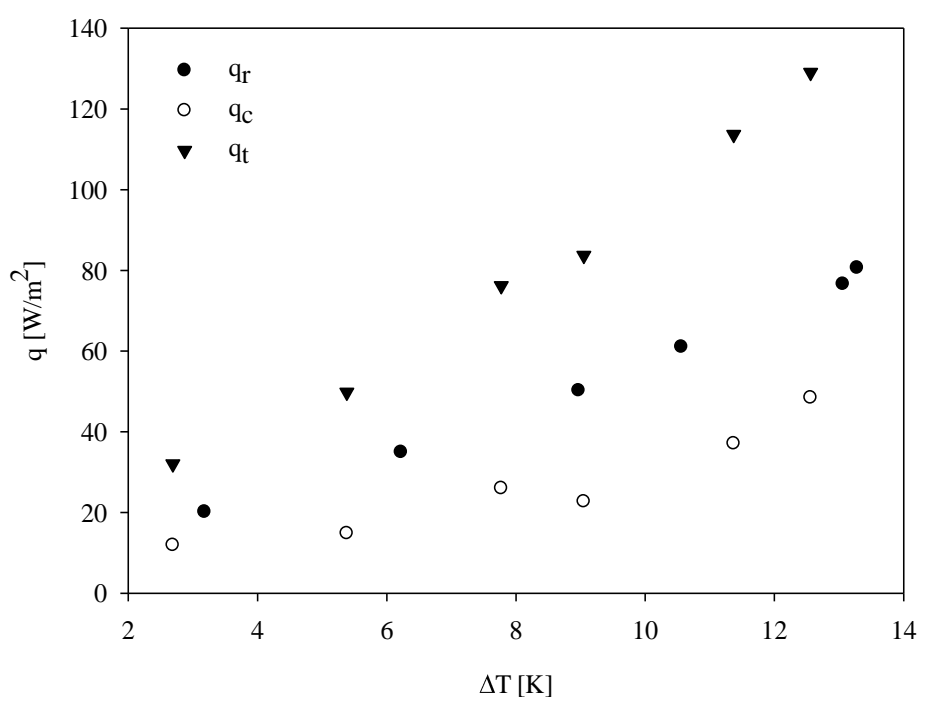

(a)

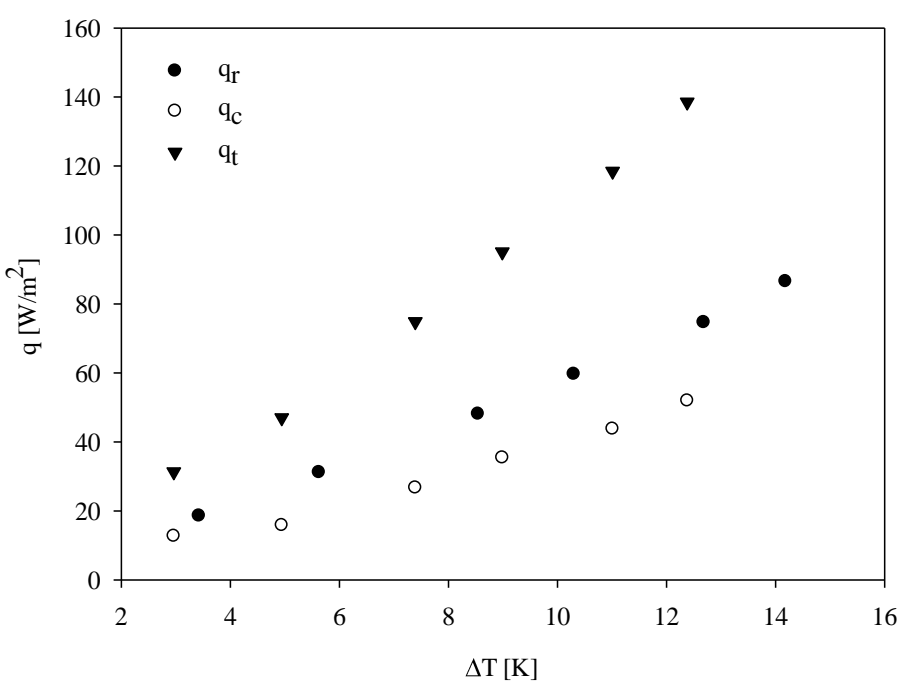

(b)

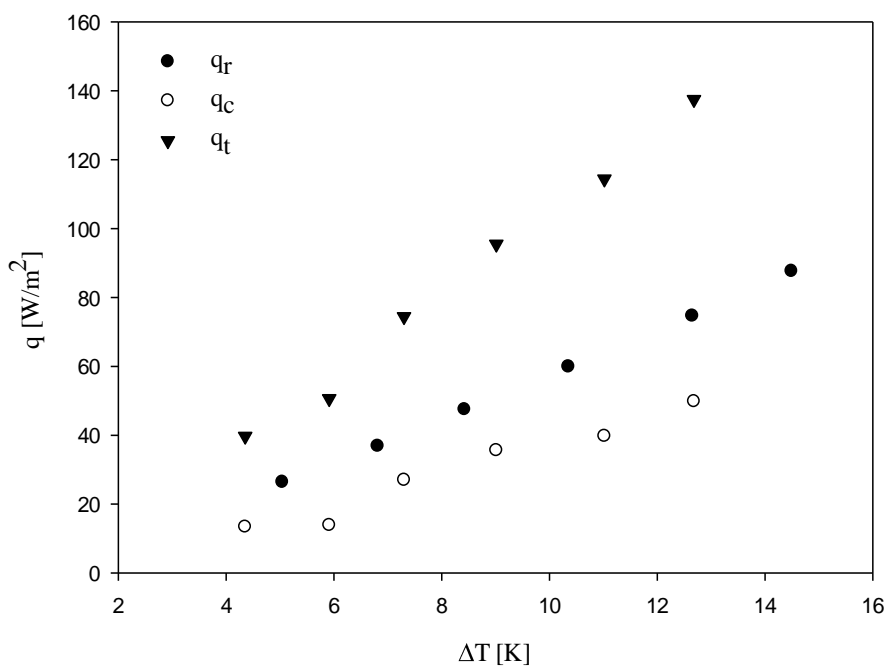

(c)

Figure 6. Alteration of radiative, convective, and total heat flux values through the examined radiant floor for $\dot{m}=0.056 \mathrm{~kg} / \mathrm{s}(\mathrm{a}), \dot{m}=0.125 \mathrm{~kg} / \mathrm{s}(\mathrm{b})$ and $\dot{m}=0.090 \mathrm{~kg} / \mathrm{s}(\mathrm{c})$ 


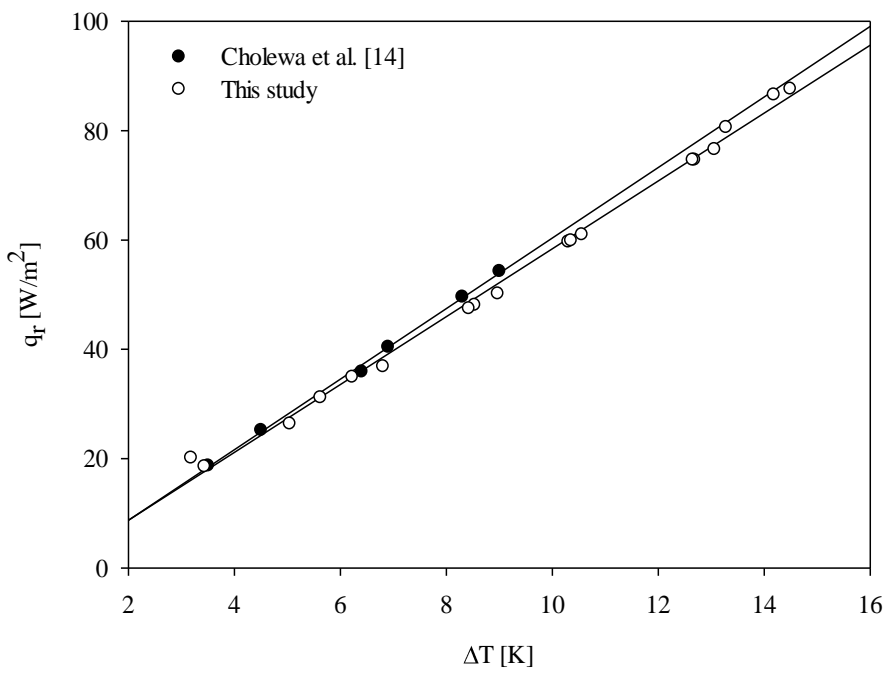

(a)

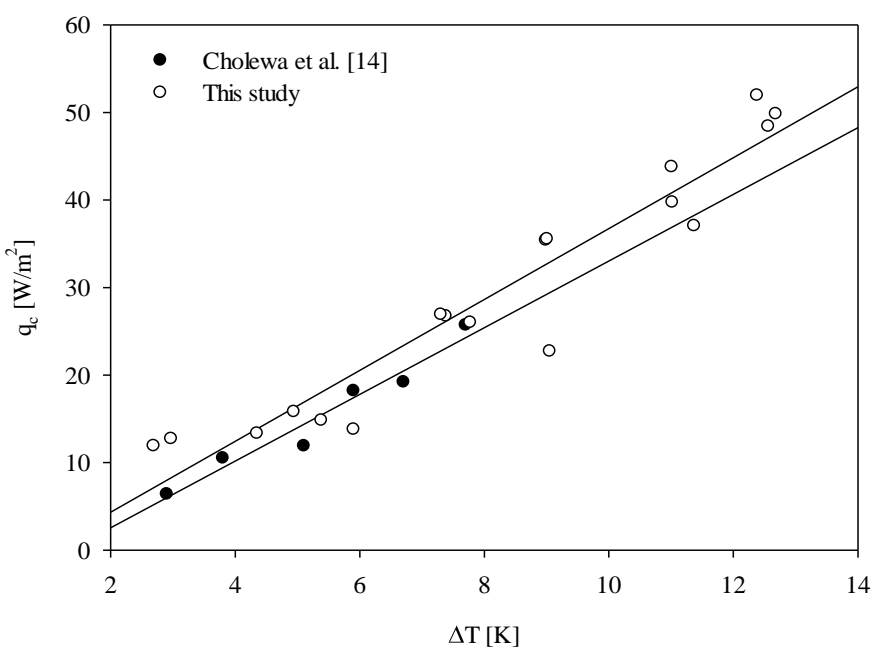

(b)

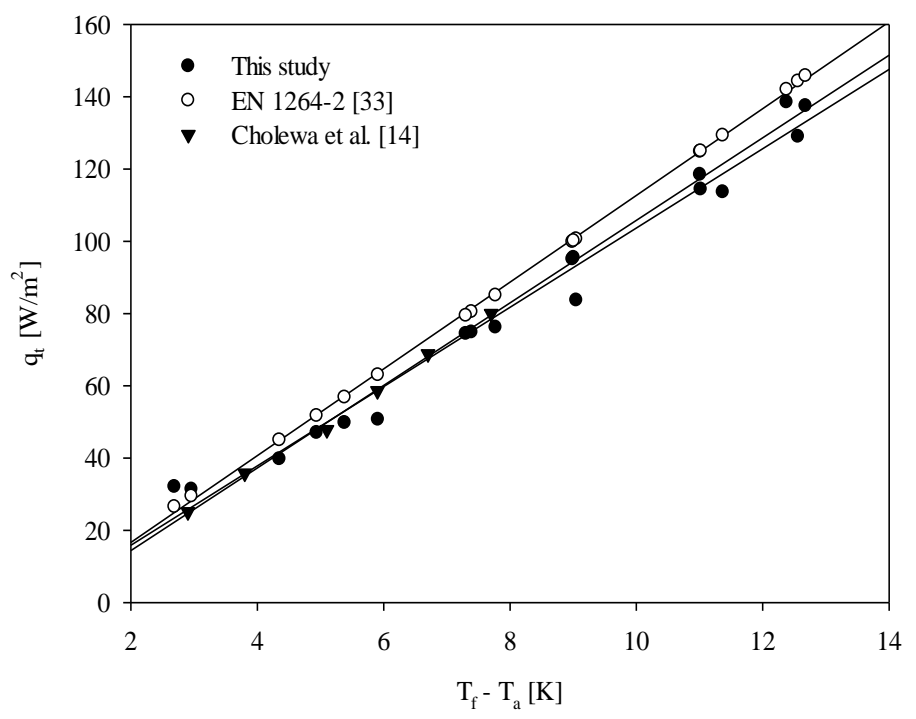

(c)

Figure 7. Variation of (a) radiative, (b) convective and (c) total heat flux values through the examined radiant floor with temperature difference and comparison with relevant literature 


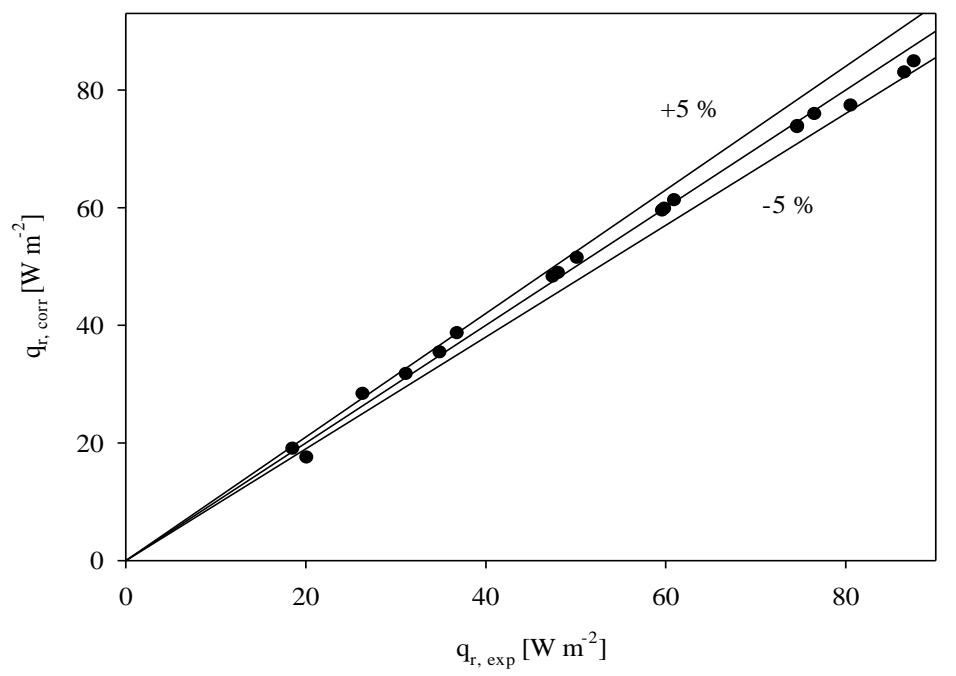

(a)

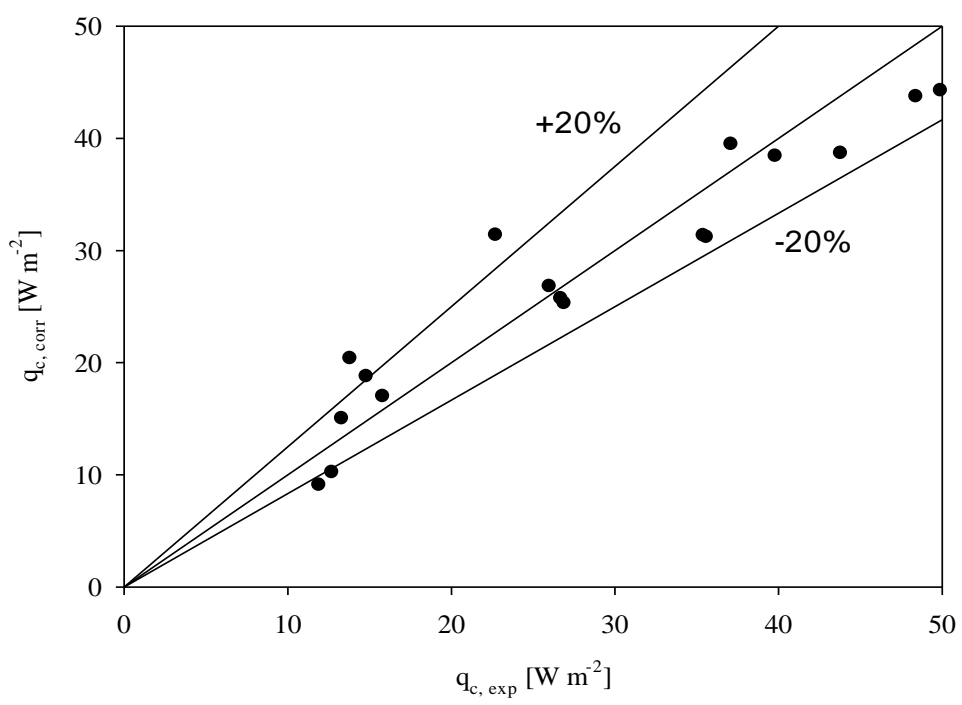

(b)

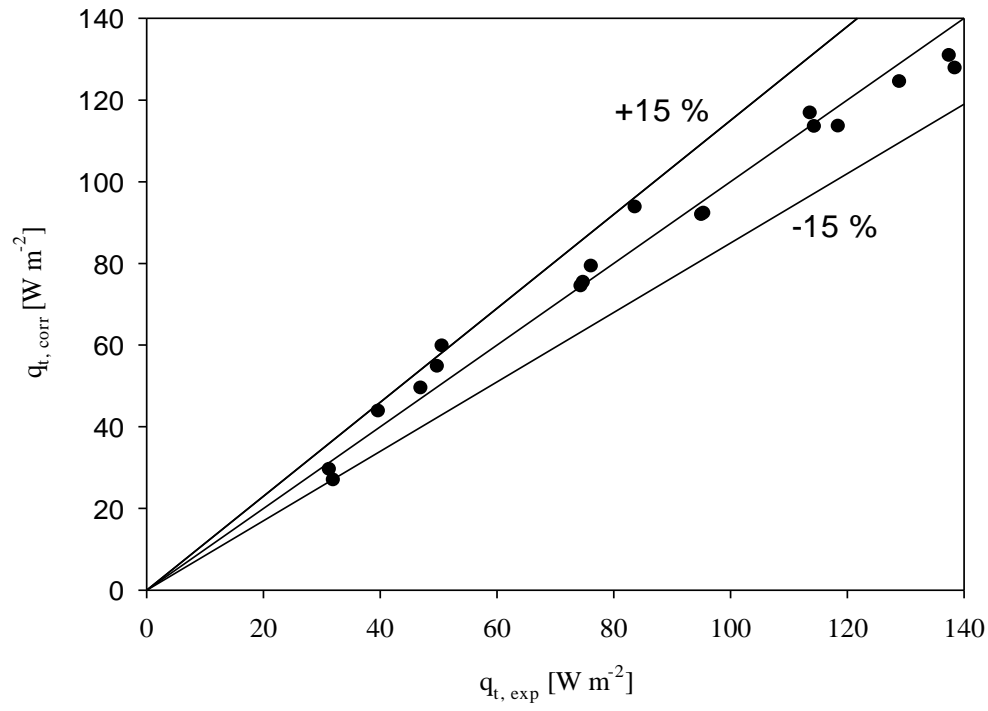

(c)

Figure 8. Comparison of the outcomes of the correlations derived for (a) adiative, (b) convective, and (c) total heat fluxes with those obtained from experiments 
Journal of Thermal Engineering, Research Article, Vol. 6, No. 5, pp. 751-771, October, 2020

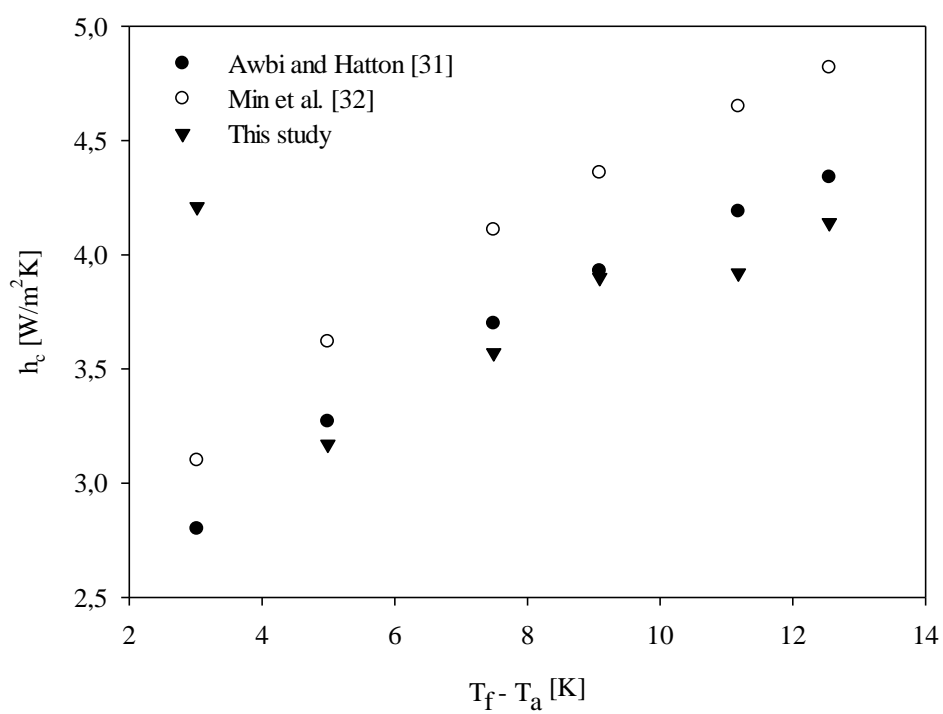

(a)

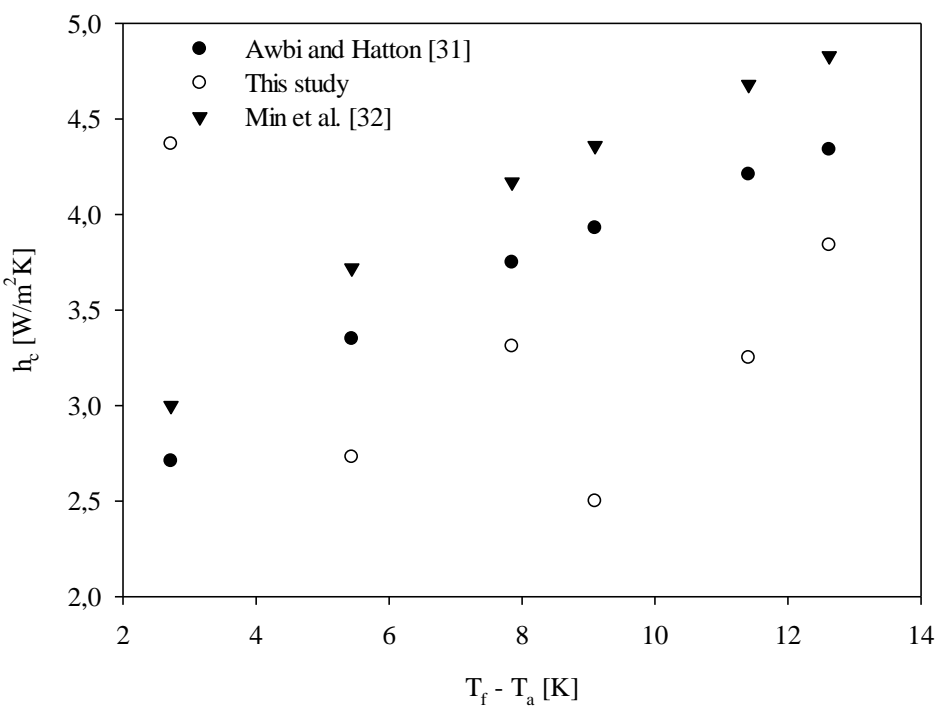

(b)

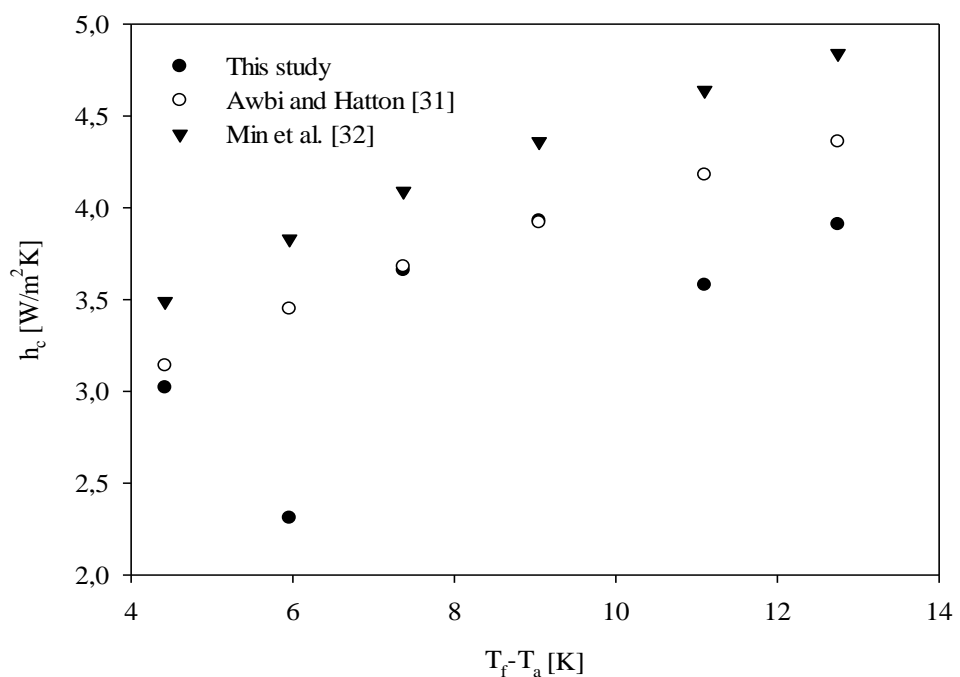

(c)

Figure 9. Convective heat transfer coefficient's variation with the temperature difference between the radiant heated floor surface and air a) $\dot{m}=0.125 \mathrm{~kg} / \mathrm{s} \mathrm{b}) \dot{m}=0.056 \mathrm{~kg} / \mathrm{s} \mathrm{c}$ ) $\dot{m}=0.090 \mathrm{~kg} / \mathrm{s}$ 
At three water flow rate values, Figures 10 (a-c) demonstrate the variation of radiative, convective, and total heat transfer coefficients with corresponding temperature difference values found using the reference temperature noted in the literature. It is obvious that just like abovementioned while remarking on figures presenting heat outputs, radiative heat transfer coefficients draw a more regular trend line, on the other hand, convective and thus total heat transfer coefficients have had a relatively dispersed behavior.

Table 4 is also a comparison source for the results of this study with the literature values with regard to radiative and total heat transfer coefficients. Moreover, as can be noticed from Figures 10 (a-c), the radiative heat transfer coefficient does not consist in the variation of water flow rate passing through the pipes composing floor heating panel, since, in all three water flow rate options performed, identical supply water temperatures $\left(\mathrm{T}_{\mathrm{s}}=30\right.$ $55^{\circ} \mathrm{C}$ ) were applied, and eventually when the measurement points within the chamber reached the steady state, roughly the same radiative heat transfer equality was established. A subtle rise is observed in radiative heat transfer coefficients in Figures 10 (a-c), and this is due to gradual growth of supply water temperature in experimental case studies. In the literature, related to radiative heat transfer coefficients, Cholewa et al. [14], Olesen et al. [34], and ASHRAE [35] recommend the values of $5.6 \mathrm{~W} / \mathrm{m}^{2} \mathrm{~K}, 5.5 \mathrm{~W} / \mathrm{m}^{2} \mathrm{~K}$, and the interval $\left(5.3-6.0 \mathrm{~W} / \mathrm{m}^{2} \mathrm{~K}\right)$, respectively, while results of this study lies within the range $5.2-6.3 \mathrm{~W} / \mathrm{m}^{2} \mathrm{~K}$ and recommendation is $5.7 \mathrm{~W} / \mathrm{m}^{2} \mathrm{~K}$. This shows that data obtained via the current investigation are compatible with relevant literature in terms of radiative heat transfer coefficients. With increasing values of radiant floor the radiative heat transfer coefficient augments simultaneously. This because of the use low temperature of heating medium to supply radiant floor. Slight differences may be accounted for by differences in dimensions of analyzed chambers which indispensably cause change in view factors in radiation calculations, differences in surface emissivity values, and diversities in radiant panel dimensions utilized.

Table 4. Comparison of the current work with relevant literature in terms of heat transfer coefficients

\begin{tabular}{|l|c|c|c|}
\hline References & $\mathbf{h}_{\mathbf{t}}$ & $\mathbf{h}_{\mathbf{c}}$ & $\mathbf{h}_{\mathbf{r}}$ \\
\hline EN 1264 - 5 [36] & 10.8 & - & - \\
\hline Cholewa et al.* [14] & $8.5-11.1$ & $2.2-3.5$ & 5.6 \\
\hline Min et al.** [32] & - & $3.0-4.8$ & - \\
\hline Awbi and Hatton ** [31] & - & $2.7-4.3$ & - \\
\hline Olesen et al. [37] & - & - & 5.5 \\
\hline ASHRAE [35] & - & $3.0-4.8$ & $5.3-6.0$ \\
\hline Present study & $10.6-11.9$ & $2.3-4.4$ & $5.2-6.3$ \\
\hline Recommendation of this study & \multicolumn{2}{|c|}{3.5} & 5.7 \\
\hline$* h_{t}$ results are obtained according to the reference temperatures of T 1.1 and $\mathrm{T}_{\mathrm{op} 0.6}$ \\
\hline$* *$ Results of correlations derived by corresponding researchers \\
\hline
\end{tabular}

In addition to above mentioned and interpreted heat transfer characteristic data, throughout the 18 experimental case studies applied within the chamber, the proportions of radiation and convection comprising total heat transfer through the heated floor have been calculated and demonstrated in Figure 11. From the data used to illustrate the figure, it is understood that nearly in all bars symbolizing each case study, a similar behavior of phenomena making up overall heat transfer is observed. 
Journal of Thermal Engineering, Research Article, Vol. 6, No. 5, pp. 751-771, October, 2020

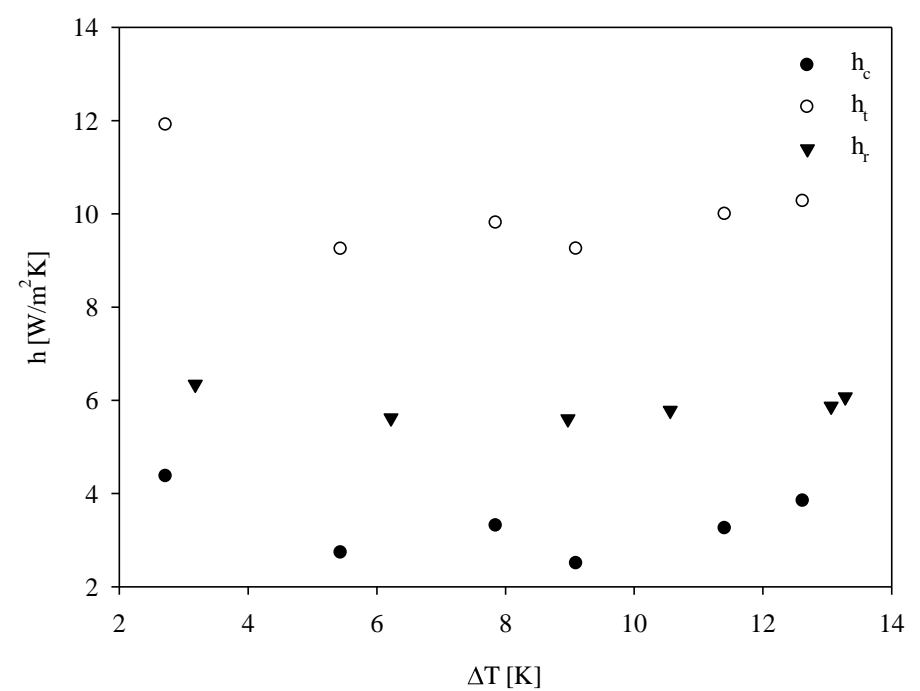

(a)

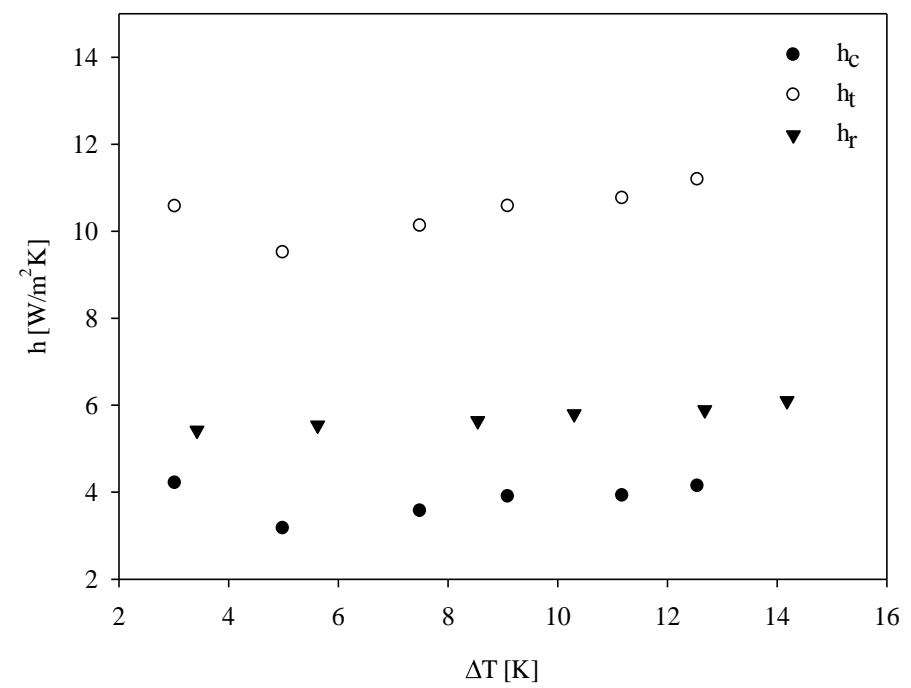

(b)

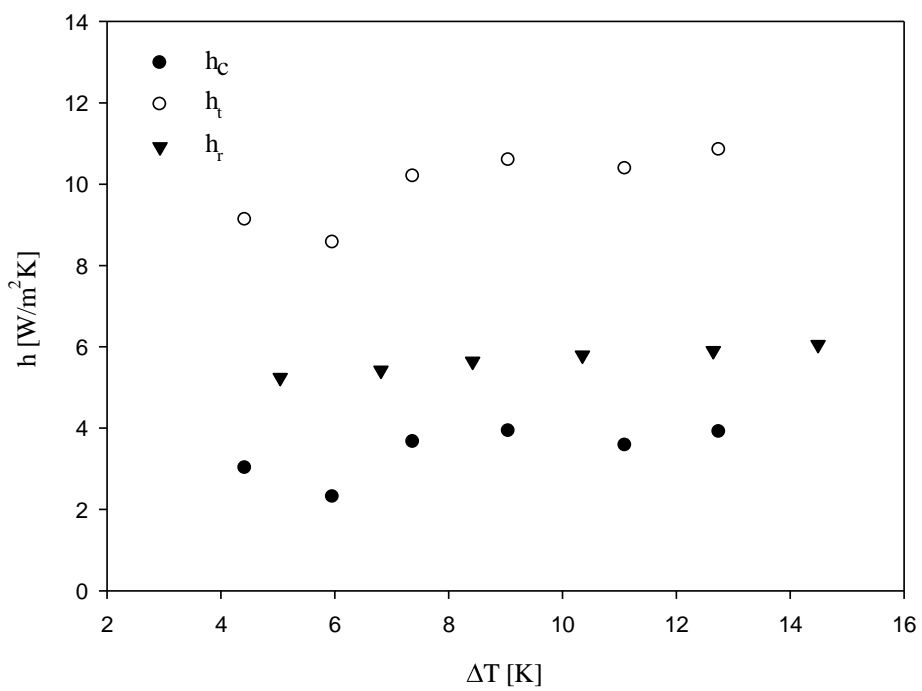

(c)

Figure 10. Change of radiative. convective. and total heat transfer coefficients with corresponding temperature differences for ( $\dot{m}=0.056 \mathrm{~kg} / \mathrm{s}$ (a), $\dot{m}=0.125 \mathrm{~kg} / \mathrm{s}$ (b) and $\dot{m}=0.090 \mathrm{~kg} / \mathrm{s} \mathrm{(c)}$ 


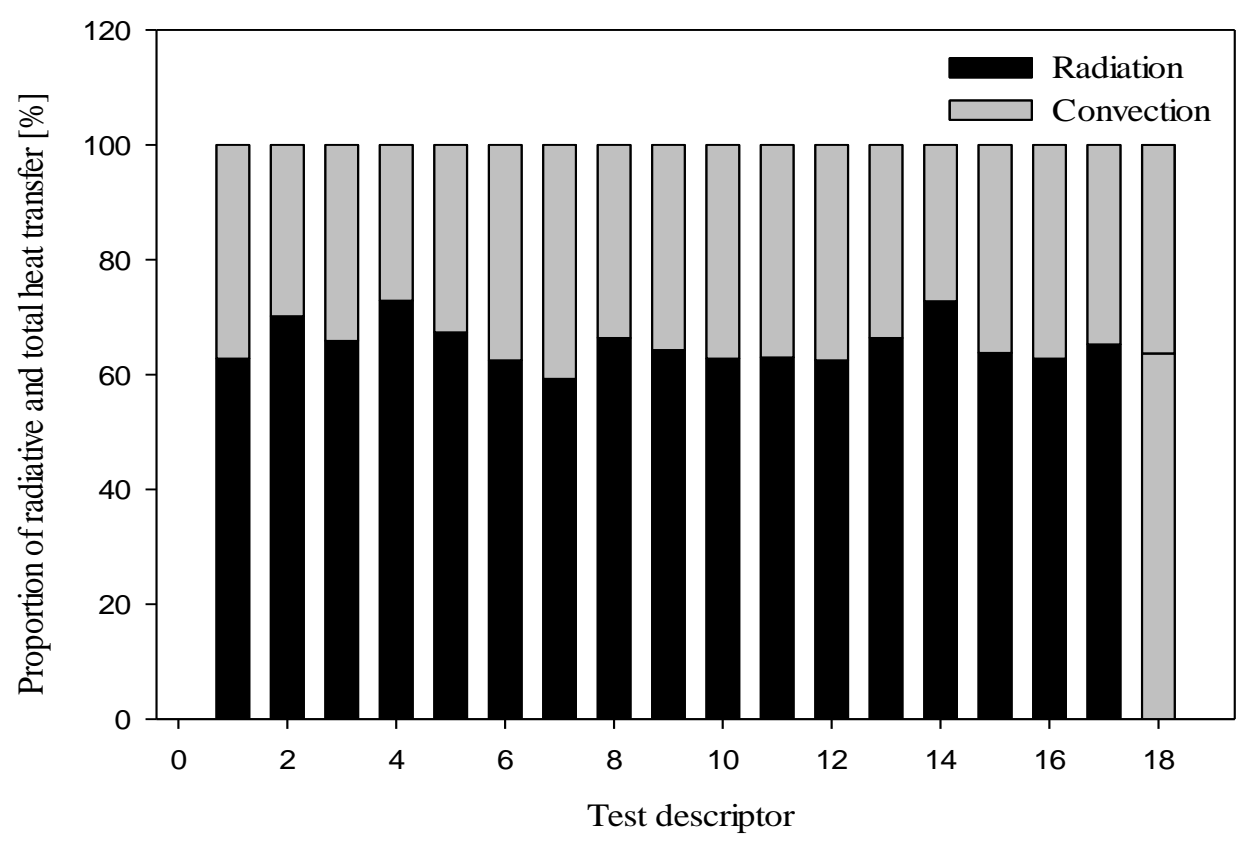

Figure 11. Proportion of radiation and convection in each case study

\section{CONCLUSION}

This paper mainly deals with an experimental approximation on the determination of heat transfer characteristics encompassing heat transfer mechanisms. Investigated hydronic radiant heated floor system has a real-sized test facility and indicates that some international standards might need reconsideration on the values of design parameters due to the advances in the technology. In order to fill this gap in open sources, working condition interval have been widened, and the experiments have been performed within extended supply water temperature and flow rate ranges of $30{ }^{\circ} \mathrm{C}$ to $55^{\circ} \mathrm{C}$ and $0.056 \mathrm{~kg} / \mathrm{s}$ to $0.125 \mathrm{~kg} / \mathrm{s}$, respectively.

The deductions of this investigation can be summarized as follows;

- It can be noticed from the results that the radiative, convective, and total outputs increase with increasing supply water temperature during the experiments, as expected.

- b. Additionally, unlike most of other studies having only a combined total heat flux correlation concerning both convection and radiation in a single form, the current one has derived new empirical correlations for convective, radiative, and total heat fluxes of which deviation bands remain within $\pm 20 \%, \pm 5 \%$, and $\pm 15 \%$, respectively.

- c. According to test results, the total and radiative heat transfer coefficients for heated radiant floor are found to be within the ranges of $8.6-11.9 \mathrm{~W} / \mathrm{m}^{2} \mathrm{~K}$ and $5.2-6.3 \mathrm{~W} / \mathrm{m}^{2} \mathrm{~K}$, respectively. Thus, it is recommended that the average total and radiative heat transfer coefficients are $10.2 \mathrm{~W} / \mathrm{m}^{2} \mathrm{~K}$ and 5.7 $\mathrm{W} / \mathrm{m}^{2} \mathrm{~K}$, respectively. It is seen that the total heat transfer coefficient recommendation of this study is lower than that of EN 1264-5 [36] by approximately $6 \%$ which is commonly used.

- d. Convective heat transfer coefficients for heated radiant floor via this study are compared with wellknown works in the literature and it is observed that similar trendlines are drawn. Nevertheless, the outcomes are found to be slightly lower than the common literature that is in the interval of $2.3-4.4 \mathrm{~W} / \mathrm{m}^{2} \mathrm{~K}$ with the recommended average value of $3.5 \mathrm{~W} / \mathrm{m}^{2} \mathrm{~K}$.

- e. The proportions of radiation and convection heat transfer through the radiant heated floor in total heat transfer have drawn the same tendency within entire experimental case studies, and the mean rate of radiation has been calculated as $60 \%$.

\section{Acknowledgements}

This study has been financially supported by Yildiz Technical University Scientific Research Projects Coordination Department, Project Number: 2015-06-01-KAP02. 
Journal of Thermal Engineering, Research Article, Vol. 6, No. 5, pp. 751-771, October, 2020

\section{NOMENCLATURE}

A Surface area $\left[\mathrm{m}^{2}\right]$

AUST Average unheated surface temperature $\left[{ }^{\circ} \mathrm{C}\right]$

$\mathrm{c}_{\mathrm{p}} \quad$ Specific heat $(\mathrm{J} / \mathrm{kgK})$

$\mathrm{F}_{\mathrm{s}-\mathrm{j}} \quad$ View factor between the radiant surface and $\mathrm{j}$ surfaces [-]

$F_{\varepsilon_{s-\mathrm{j}}} \quad$ Radiation interchange factor [-]

$\mathrm{h}_{\mathrm{c}} \quad$ Convective heat transfer coefficient $\left[\mathrm{W} / \mathrm{m}^{2} \mathrm{~K}\right]$

$\mathrm{h}_{\mathrm{r}} \quad$ Radiative heat transfer coefficient $\left[\mathrm{W} / \mathrm{m}^{2} \mathrm{~K}\right]$

$\mathrm{h}_{\mathrm{t}} \quad$ Total heat transfer coefficient $\left[\mathrm{W} / \mathrm{m}^{2} \mathrm{~K}\right]$

$\dot{\boldsymbol{m}}_{\mathrm{w}} \quad$ Mass flow rate $[\mathrm{kg} / \mathrm{s}]$

$\mathrm{Q}_{\mathrm{c}} \quad$ Convective heat transfer [W]

$\mathrm{Q}_{\mathrm{r}} \quad$ Radiative heat transfer [W]

$\mathrm{q}_{\mathrm{c}} \quad$ Convective heat flux $\left[\mathrm{W} / \mathrm{m}^{2}\right]$

$\mathrm{q}_{\mathrm{r}} \quad$ Radiative heat flux $\left[\mathrm{W} / \mathrm{m}^{2}\right]$

$\mathrm{q}_{\mathrm{t}} \quad$ Total heat flux $\left[\mathrm{W} / \mathrm{m}^{2}\right]$

$\mathrm{q}_{\mathrm{c}, \exp } \quad$ Convective heat flux-experimental $\left[\mathrm{W} / \mathrm{m}^{2}\right]$

$\mathrm{q}_{\mathrm{c}, \text { corr }}$ Convective heat flux-correlation $\left[\mathrm{W} / \mathrm{m}^{2}\right]$

$\mathrm{q}_{\mathrm{t}, \text { exp }} \quad$ Total heat flux-experimental $\left[\mathrm{W} / \mathrm{m}^{2}\right]$

$\mathrm{q}_{\mathrm{t}, \text { corr }} \quad$ Total heat flux-correlation $\left[\mathrm{W} / \mathrm{m}^{2}\right]$

$\mathrm{q}_{\mathrm{r}, \exp }$ Convective heat flux-experimental $\left[\mathrm{W} / \mathrm{m}^{2}\right]$

$\mathrm{q}_{\mathrm{r}, \text { corr }}$ Convective heat flux-correlation $\left[\mathrm{W} / \mathrm{m}^{2}\right]$

$\mathrm{T}_{\mathrm{a}} \quad$ Air temperature $\left[{ }^{\circ} \mathrm{C}\right]$

$\mathrm{T}_{\text {op }} \quad$ Operative temperature $\left[{ }^{\circ} \mathrm{C}\right]$

$\mathrm{T}_{\mathrm{f}} \quad$ Heated floor temperature $\left[{ }^{\circ} \mathrm{C}\right]$

$\mathrm{T}_{\mathrm{s}} \quad$ Supply water temperature $\left[{ }^{\circ} \mathrm{C}\right]$

$\mathrm{T}_{\mathrm{c}} \quad$ Ceiling temperature $\left[{ }^{\circ} \mathrm{C}\right]$

$\mathrm{T}_{\mathrm{w}} \quad$ Wall temperature $\left[{ }^{\circ} \mathrm{C}\right]$

$\Delta \mathrm{T} \quad$ Temperature difference between radiant heated floor and reference temperature $\left[{ }^{\circ} \mathrm{C}\right]$

Greek symbols

$\varepsilon \quad$ Surface emissivity [-]

$\sigma \quad$ Stefan-Boltzmann constant $\left[\mathrm{W} / \mathrm{m}^{2} \mathrm{~K}^{4}\right]$ 
Journal of Thermal Engineering, Research Article, Vol. 6, No. 5, pp. 751-771, October, 2020

\section{REFERENCES}

[1] Awbi HB. Calculation of convective heat transfer coefficients of room surfaces for natural convection. Energy Build 1998. https://doi.org/10.1016/s0378-7788(98)00022-x.

[2] Hasan A, Kurnitski J, Jokiranta K. A combined low temperature water heating system consisting of radiators and floor heating. Energy Build 2009. https://doi.org/10.1016/j.enbuild.2008.11.016.

[3] Myhren JA, Holmberg S. Flow patterns and thermal comfort in a room with panel, floor and wall heating. Energy Build 2008. https://doi.org/10.1016/j.enbuild.2007.04.011.

[4] Myhren JA, Holmberg S. Design considerations with ventilation-radiators: Comparisons to traditional two-panel radiators. Energy Build 2009. https://doi.org/10.1016/j.enbuild.2008.07.014.

[5] Li QQ, Chen C, Zhang Y, Lin J, Ling HS. Simplified thermal calculation method for floor structure in radiant floor cooling system. Energy Build 2014. https://doi.org/10.1016/j.enbuild.2014.01.032.

[6] Tye-Gingras M, Gosselin L. Investigation on heat transfer modeling assumptions for radiant panels with serpentine layout. Energy Build 2011. https://doi.org/10.1016/j.enbuild.2011.03.004.

[7] Karabay H, Arici M, Sandik M. A numerical investigation of fluid flow and heat transfer inside a room for floor heating and wall heating systems. Energy Build 2013;67:471-8. https://doi.org/10.1016/j.enbuild.2013.08.037.

[8] Causone F, Baldin F, Olesen BW, Corgnati SP. Floor heating and cooling combined with displacement ventilation: Possibilities and limitations. Energy Build 2010. https://doi.org/10.1016/j.enbuild.2010.08.001.

[9] Koca A, Gemici Z, Topacoglu Y, Cetin G, Acet RC, Kanbur BB. Experimental investigation of heat transfer coefficients between hydronic radiant heated wall and room. Energy Build 2014. https://doi.org/10.1016/j.enbuild.2014.06.045.

[10] Bojić M, Cvetković D, Marjanović V, Blagojević M, Djordjević Z. Performances of low temperature radiant heating systems. Energy Build 2013;61:233-8. https://doi.org/10.1016/j.enbuild.2013.02.033.

[11] Seyam S, Huzayyin A, El-Batsh H, Nada S. Experimental and numerical investigation of the radiant panel heating system using scale room model. Energy Build 2014. https://doi.org/10.1016/j.enbuild.2014.07.003.

[12] Rahimi M, Sabernaeemi A. Experimental study of radiation and free convection in an enclosure with under-floor heating system. Energy Convers Manag 2011;52:2752-7. https://doi.org/10.1016/j.enconman.2011.02.020.

[13] Andrés-Chicote M, Tejero-González A, Velasco-Gómez E, Rey-Martínez FJ. Experimental study on the cooling capacity of a radiant cooled ceiling system. Energy Build 2012. https://doi.org/10.1016/j.enbuild.2012.07.043.

[14] Cholewa T, Rosiński M, Spik Z, Dudzińska MR, Siuta-Olcha A. On the heat transfer coefficients between heated/cooled radiant floor and room. Energy Build 2013;66:599-606. https://doi.org/10.1016/j.enbuild.2013.07.065.

[15] Causone F, Corgnati SP, Filippi M, Olesen BW. Experimental evaluation of heat transfer coefficients between radiant ceiling and room. Energy Build 2009. https://doi.org/10.1016/j.enbuild.2009.01.004.

[16] Tian Z, Yin X, Ding Y, Zhang C. Research on the actual cooling performance of ceiling radiant panel. Energy Build 2012. https://doi.org/10.1016/j.enbuild.2012.01.005.

[17] Zhang L, Liu XH, Jiang Y. Experimental evaluation of a suspended metal ceiling radiant panel with inclined fins. Energy Build 2013. https://doi.org/10.1016/j.enbuild.2013.03.044.

[18] Li R, Yoshidomi T, Ooka R, Olesen BW. Field evaluation of performance of radiant heating/cooling ceiling panel system. Energy Build 2015. https://doi.org/10.1016/j.enbuild.2014.09.070.

[19] Fontana L. Thermal performance of radiant heating floors in furnished enclosed spaces. Appl Therm Eng 2011;31:1547-55. https://doi.org/10.1016/j.applthermaleng.2010.12.014.

[20] Acikgoz O, Karakoyun Y, Yumurtacı Z, Dukhan N, Dalkılıç AS. Realistic experimental heat transfer characteristics of radiant floor heating using sidewalls as heat sinks. Energy Build 2019;183:515-26. https://doi.org/10.1016/j.enbuild.2018.11.022.

[21] Karakoyun Y, Acikgoz O, Yumurtacı Z, Dalkilic AS. An experimental investigation on heat transfer characteristics arising over an underfloor cooling system exposed to different radiant heating loads through walls. Appl Therm Eng 2020;164. https://doi.org/10.1016/j.applthermaleng.2019.114517.

[22] Xia Y, Zhang XS. Experimental research on a double-layer radiant floor system with phase change material under heating mode. Appl Therm Eng 2016. https://doi.org/10.1016/j.applthermaleng.2015.11.133.

[23] Acikgoz O, Kincay O. Experimental and numerical investigation of the correlation between radiative and convective heat-transfer coefficients at the cooled wall of a real-sized room. Energy Build 2015. https://doi.org/10.1016/j.enbuild.2015.09.013.

[24] Acikgoz O. A novel evaluation regarding the influence of surface emissivity on radiative and total heat transfer coefficients in radiant heating systems by means of theoretical and numerical methods. Energy 
Build 2015;102:105-16. https://doi.org/10.1016/j.enbuild.2015.05.016.

[25] Acikgoz O, Kincay O. Numerical determination of effects of wall temperatures on nusselt number and convective heat transfer coefficient in real-size rooms. Adv Mech Eng 2013. https://doi.org/10.1155/2013/287963.

[26] Acikgoz O, Çebi A, Dalkilic AS, Koca A, Çetin G, Gemici Z, et al. A novel ANN-based approach to estimate heat transfer coefficients in radiant wall heating systems. Energy Build 2017. https://doi.org/10.1016/j.enbuild.2017.03.043.

[27] Hu R, Niu JL. A review of the application of radiant cooling \& heating systems in Mainland China. Energy Build 2012. https://doi.org/10.1016/j.enbuild.2012.05.030.

[28] Shinoda J, Kazanci OB, Tanabe S ichi, Olesen BW. A review of the surface heat transfer coefficients of radiant heating and cooling systems. Build Environ 2019. https://doi.org/10.1016/j.buildenv.2019.05.034.

[29] Peeters L, Beausoleil-Morrison I, Novoselac A. Internal convective heat transfer modeling: Critical review and discussion of experimentally derived correlations. Energy Build 2011. https://doi.org/10.1016/j.enbuild.2011.05.002.

[30] Kline S, McClintock F. Describing uncertainties in single-sample experiments. Mech Eng 1953.

[31] H.B. Awbi, A. Hatton. Natural convection from heated room surfaces. Energy Build 30 1999;7788:233244. https://doi.org/10.1016/S0378-7788(99)00004-3.

[32] Min TC, Schutrum LF, Parmelee GV VJ. Natural convection and radiation in a panel heated room. ASHRAE Trans 1956;62:337-58.

[33] EN 1264-2 Water Based Surface Embedded Heating and Cooling Systems - Part2: Floor Heating Prove Methods for the Determination of the Thermal Output Using Calculation and Test Methods. 2008.

[34] Olesen BW. Radiant floor heating in theory and practice. ASHRAE J 2002.

[35] ASHRAE. Handbook HVAC Fundamentals. vol. 30329. 2009.

[36] EN 1264-5 Water based surface embedded heating and cooling systems, in: Part 5: Heating and Cooling Surfaces Embedded in Floors, Ceilings and Walls - Determination of the Thermal Output. 2008.

[37] Olesen BW, Koschenz M, Johansson C. New European standard proposal for design and dimensioning of embedded radiant surface heating and cooling systems. ASHRAE Trans 2003;109 PART 2:656-68. 